\title{
Nanotargeted Radionuclides for Cancer Nuclear Imaging and Internal Radiotherapy
}

\author{
Gann Ting, ${ }^{1}$ Chih-Hsien Chang, ${ }^{2,3}$ Hsin-Ell Wang, ${ }^{3}$ and Te-Wei Lee ${ }^{2}$ \\ ${ }^{1}$ Center of Nanomedicine and National Institute of Cancer Research, National Health Research Institutes, 35053 Miaoli, Taiwan \\ ${ }^{2}$ Isotope Application Division, Institute of Nuclear Energy Research, 32546 Taoyuan, Taiwan \\ ${ }^{3}$ Biomedical Imaging and Radiological Sciences, National Yang-Ming University, 11221 Taipei, Taiwan
}

Correspondence should be addressed to Gann Ting, gann.ting@msa.hinet.net

Received 13 April 2010; Accepted 15 June 2010

Academic Editor: David J. Yang

Copyright (C) 2010 Gann Ting et al. This is an open access article distributed under the Creative Commons Attribution License, which permits unrestricted use, distribution, and reproduction in any medium, provided the original work is properly cited.

\begin{abstract}
Current progress in nanomedicine has exploited the possibility of designing tumor-targeted nanocarriers being able to deliver radionuclide payloads in a site or molecular selective manner to improve the efficacy and safety of cancer imaging and therapy. Radionuclides of auger electron-, $\alpha$-, $\beta$-, and $\gamma$-radiation emitters have been surface-bioconjugated or after-loaded in nanoparticles to improve the efficacy and reduce the toxicity of cancer imaging and therapy in preclinical and clinical studies. This article provides a brief overview of current status of applications, advantages, problems, up-to-date research and development, and future prospects of nanotargeted radionuclides in cancer nuclear imaging and radiotherapy. Passive and active nanotargeting delivery of radionuclides with illustrating examples for tumor imaging and therapy are reviewed and summarized. Research on combing different modes of selective delivery of radionuclides through nanocarriers targeted delivery for tumor imaging and therapy offers the new possibility of large increases in cancer diagnostic efficacy and therapeutic index. However, further efforts and challenges in preclinical and clinical efficacy and toxicity studies are required to translate those advanced technologies to the clinical applications for cancer patients.
\end{abstract}

\section{Introduction}

Cancer an up-regulated biological process of cell growth with an ability of tumor cells to invade and metastasize. A century ago, Paul Ehrlich hypothesized that a "magic bullet" could be developed to selectively target cancer [1]. Over the past few decades, the progress in molecular biology and the understanding of malignant transformation and tumorigenesis have revealed two major classes of antitumor therapeutics: (i) application of molecularly targeted therapeutics to block major hallmarks of cancer cells, and (ii) employing drug delivery systems through tumor-targeted nanomedicines to improve the pharmacokinetics and bioavailability of vehiclecarried drugs. Targeted cancer therapies can be defined as drugs developed against a specific tumor target according to its important biology function in cancer. From 1980 to 2005, a total of 205 monoclonal antibodies $(\mathrm{mAb})$ were studied in clinical trials [2-5]. The US Food and Drug Administration (FDA) approved the first anti-CD20 mAb (Rituximab) for the treatment of non-Hodgkin's lymphoma in 1997. Today, twelve of these anticancer molecular-targeted mAbs have been approved worldwide, eight of them were approved by US FDA [3-5].

Conventional anticancer drugs exhibit a lack of specificity, poor solubility and distribution, unfavorable pharmacokinetics, and high-tissue damage or toxicity. Nanotechnology can bring fundamental changes to the study and understanding of biological processes in health and disease, as well as enable novel diagnostics and therapeutics for treating cancer. Thus, advances made on the basis of nanotechnology could result in progress of healthcare. Targeted drug delivery systems such as passive and active targeting nanoparticles or nanocarriers, with diameters ranging from $10-100 \mathrm{~nm}$, have been developed to improve the biodistribution, pharmacological, therapeutic and toxicity properties of agents used in cancer diagnostics and therapeutics [6-12]. The status of the development of targeting delivery systems, including targeting strategies, potential applications, and the prospects 
of tumor-targeted nanocarriers have been reviewed and discussed [6-11]. Nanotechnology is attracting increasing attention in the biomedical community, owing to unique prospects for targeted delivery in imaging, therapy, and drug delivery. Cancer nanotechnology is expected to transform current treatment systems by providing more efficient cancer diagnostics and therapeutics. Today, nanocarriers are used in detecting cancer at an early stage, delivering anticancer drugs specifically to malignant cells, and determining if these drugs are killing malignant cells [9-13]. Two therapeutic nanocarrier-liposomes and albumin nanoparticles have been approved by US FDA for clinical practices [8, 12, 13]. Pegylated liposomal doxorubicin represents a new class of chemotherapy delivery system that may significantly improve the therapeutic index of doxorubicin through improving therapeutic pharmacokinetics [6]. As nanocarriers are evaluated for safety and efficacy, nanotechnology will bring with it significant advances in molecular imaging and specific targeting of tumor therapeutic agents, elevating therapeutic efficacy, and finally achieving the goal of early detection and control of cancer. Customized nanoscale constructs can serve as targeted drug delivery vehicles capable of delivering large doses of radionuclide or chemotherapeutic agents into malignant cells while sparing normal tissues, greatly reducing the side-effects that usually accompany many current cancer therapies [8-13].

Monoclonal antibody-guided radiation therapy, or radioimmunotherapy, demonstrated promise in preclinical and clinical anticancer applications [14-19]. The principles and applications of molecular targeting involving radionuclide methods for tumor nuclear imaging and therapy were reviewed and discussed [19]. Two radiolabeled anti-CD20 monoclonal antibodies ${ }^{90}$ Y-ibritumomab (Zevalin) and ${ }^{131} \mathrm{I}-$ tositumomab (Bexxar) were approved by US FDA in 2002 and 2003, respectively, for treatment of B-cell non-Hodgkin's lymphoma (NHL), which indicates the potential benefit of antibody-guided systemic radionuclide-targeted therapy [16-18]. However, tumor targeting studies with radiolabeled mAbs also showed some limitations, such as, inefficient targeting and low accumulation in tumor sites $(<0.1 \%$ of injection dose per gram (\%ID/g) of tumor for human) and irradiation of normal tissues for long circulation of mAbs. Emerging new methods for improving the specific uptake of radionuclides in tumor cells while sparing the normal tissues need to be established. Several advanced strategies for radionuclide-targeted delivery have been studied extensively, including the combination of chemotherapy agents with particle-emitting radionuclides and the development of novel multimodality and multifunctional nanotargeted therapeutics [20, 21]. Optimization of treatment protocols has significantly improved the therapeutic efficacy and reduced toxicity in normal tissues. Nanoparticles delivering radionuclides for improving pharmacokinetics and therapeutic efficacy of cancer have been presented elsewhere [20$22]$. The goal of this article is to review and summarize the recent research progress and future prospects of advanced nanoparticles or nanocarriers to deliver radionuclides for cancer in vivo nuclear imaging and therapeutic applications.

\section{Nanoparticles and Radionuclides for Tumor Nuclear Imaging and Internal Radiotherapy}

2.1. Nanoparticles for Tumor Nuclear Imaging and Radiotherapy. Major challenges of drug delivery carriers in cancer diagnostics and therapeutics are the low drug bioavailability within cancer cells and the high toxicities to normal organs $[22,23]$. Targeted radionuclide therapy is often limited by insufficient delivery of radionuclides to tumor sites using the currently available targeting strategies, such as monoclonal antibodies and peptides, due to relatively low and heterogeneous expression of receptors on tumor cells, as well as dose-limiting toxicities to normal tissues. To maximize the therapeutic index and to minimize the toxicity, it is very important to deliver the radionuclides to the right site at the right concentration and at the right time. The rapidly advancing field of cancer nanotechnology has generated several innovative radionuclides and drug delivery systems, such as liposomes [23-31], iron oxide [32-34], polymers [35], dendrimers [36], quantum dots [37-39], and carbon nanotubes [40], to improve and enhance targeted transport of cytotoxic drugs or radionuclides to tumor lesions [20-23, 41, 42]. It is estimated that approximately 240 nano-enabled products entered pharmaceutical research pipelines in 2006 [43]. These nanocarrier systems could provide the delivery platforms needed for improving the delivery of radionuclides to tumor sites. Nanoparticles or nanocarrier delivery systems have also revealed enhanced imaging and therapeutic efficacy by targeted delivery of drugs to the tumor site and by reducing their toxic side-effects [7-13]. Major advantages of nanocarriers are that they can be prepared in sizes $<100 \mathrm{~nm}$, and increase selectively the localization of drugs and radionuclides in the tumor through their nanosize or enhanced permeability and retention (EPR) effect of passive targeting to the leaky tumor tissues [20, 21], or nanoparticle surface bio-conjugation, while sparing nontargeted tissue, ensuring minimal drug or radionuclide leakage during circulation, and facilitating intracellular drug or radionuclide delivery and uptake by active targeting [22, $23,41,42,44]$. Two major mechanisms for radionuclide- or drug-targeted accumulation delivery system of nanoparticles to tumor tissue sites are (i) site-specific passive tumor targeting and (ii) molecular affinity and site-specific active tumor targeting for tumor diagnostics and therapy as shown in Figure 1(a) [7].

There are three generations of nanocarriers or nanoparticles developed: (i) the first generation of nanocarriers (passive targeting) which are rapidly trapped in the reticuloendothelial system (RES) organs (e.g., liver and/or spleen) [25-27, 29, 31], (ii) the second generation of sterically stabilized PEGylated nanocarriers (passive targeting), which can evade the RES of the liver and spleen, enjoys a prolonged circulation in the blood and allows for passive targeting through the enhanced permeability and retention (EPR) effect in leaky tumor tissues [25-27, 29, 31], and (iii) the third generation of nanocarriers with a bioconjugated surface modification of the nanoparticles using specific antibodies or peptides to actively target specific tumor or tissues through molecular interaction or affinity 

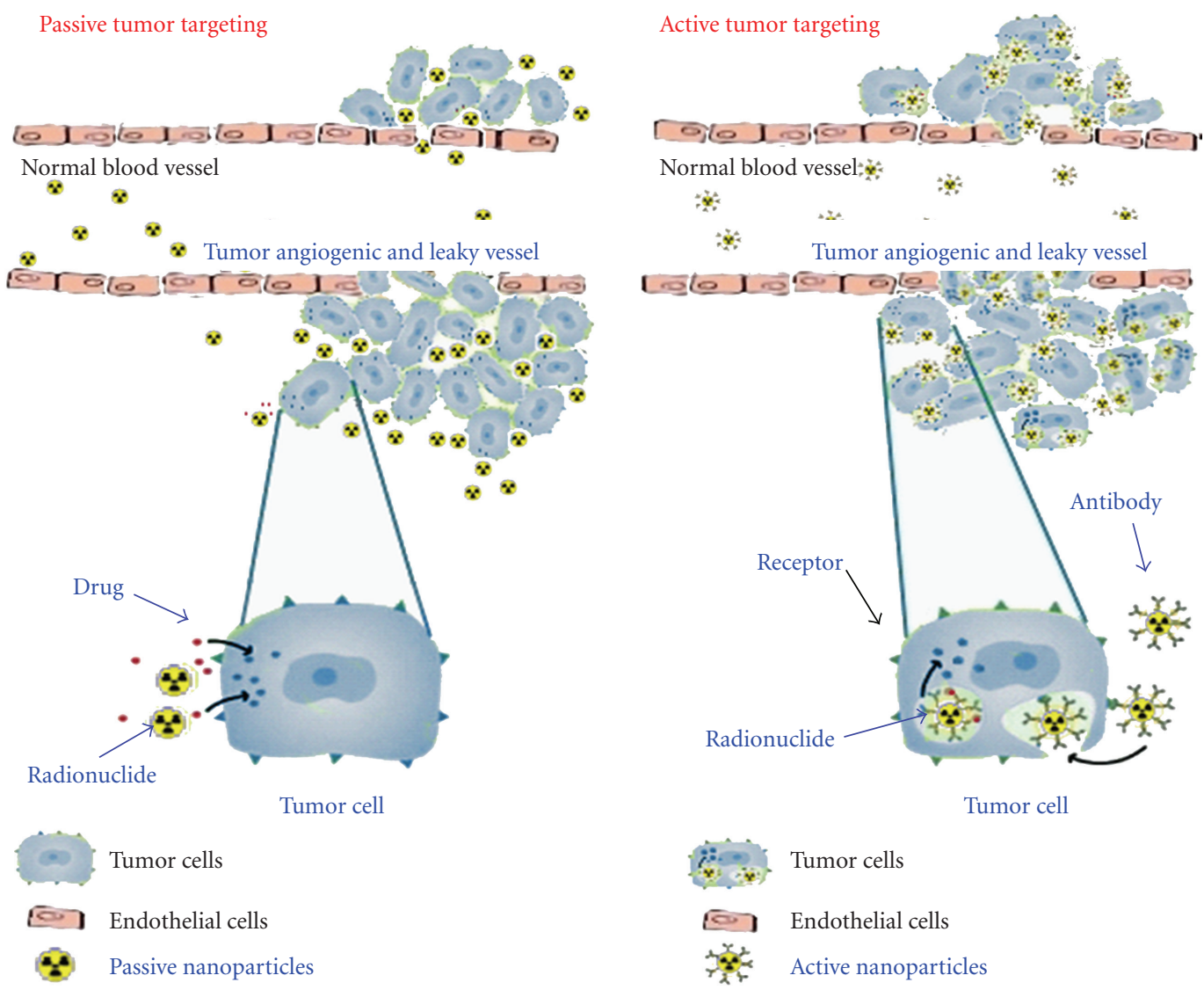

Tumor cell

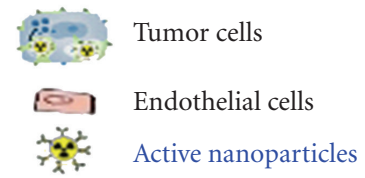

(a)

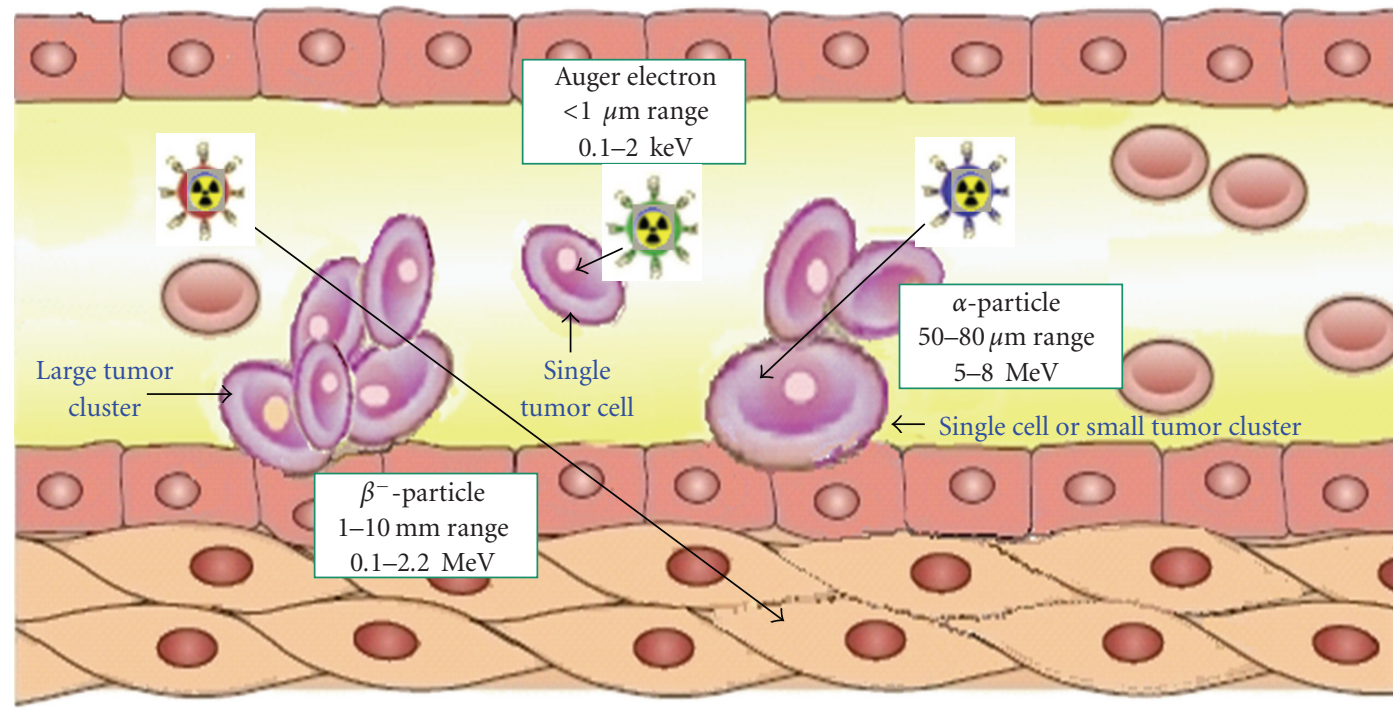

(b)

Figure 1: (a) Schematic illustration showing the possible mechanism for radionuclides or drug accumulation delivery system of nanoparticles by site specific passive tumor targeting using the enhanced permeability and retention (EPR) effect or molecular affinity and site specific active tumor targeting through ligand tumor cell surface receptors interaction, internalization, and intracellular action for tumor diagnostics and therapy (reproduced with modification with permission from [7]). (b) Schematic diagram of tumor tissue penetration range of internal radiotherapy by auger electron $(0.1-2 \mathrm{keV},<1 \mu \mathrm{m})-, \alpha(5-8 \mathrm{MeV}, 50-80 \mu \mathrm{m}$ range)-, and $\beta(0.1-2.2 \mathrm{MeV}, 1-10 \mathrm{~mm}$ range )radiation emitters for passively and actively nanotargeted radionuclide therapy (reproduced with modification with permission from [14]). 
(active targeting) [22, 32-42, 44-52]. The pharmacokinetics and bioavailability of drugs and radionuclides delivered by the third-generation nanocarriers have been much improved. There are three major challenges of applying nanoparticles to delivery of drugs or radionuclides: (i) synthesizing nanocarriers with stealth characteristics which are able to decrease uptake of delivered diagnostic and therapeutic agents in the reticuloendothelial system (RES) and prolong blood circulation, (ii) producing multifunctional nanoparticles with improved in vivo targeting capabilities, and interaction with disease biomarkers at the molecular level, (iii) developing reliable approaches to test these new materials in vitro and in vivo for a fast translation from the bench to the bedside $[21,42]$.

There are five approaches generally used for labeling or encapsulating radionuclides on nanoparticles: (i) labeling nanocarriers by encapsulation during preparation, (ii) nanocarriers surface labeling after preparation, (iii) nanocarrier surface labeling of bioconjugates after preparation, (iv) incorporation into the lipid bilayer after preparation, and (v) after-loading of the aqueous phase of the nanocarriers after preparation. The after-loading method has provided higher labeling efficiencies (>90\%) and the greatest in vivo stability for ${ }^{99 \mathrm{~m}} \mathrm{Tc},{ }^{111} \mathrm{In}$, and ${ }^{67} \mathrm{Ga}$ radionuclides for nuclear imaging $[20,21,24,30,31,42,53]$.

\subsection{Radionuclides for Tumor Nuclear Imaging and Radio-} therapeutics. The research on tumor-targeted diagnostic and therapeutic radionuclides is one of the potential areas of cancer drug development. Normally, targeted radionuclides consist of two components, a targeting carrier and a trace amount of radionuclide with a specific radiation emitter. The tumor therapeutic efficacy and diagnostic quality are determined by the selectivity or specificity of the targeted delivery systems and the radionuclide radiation characteristics $[14,15,20,21]$. The selection of potential targeted radionuclides for tumor imaging (Table 1) and targeted radionuclide for internal radiotherapy (Table 2) involves the physical half-life, decay mode, and the emission properties of the radionuclides. Gamma emitters with energy range between 130 and $370 \mathrm{keV}$ can be used for gamma imaging or single photon emission tomography (SPECT) [24-30]. The high-energy positron emitters with annihilation energy at $511 \mathrm{keV}$ energy can be applied for positron-emission tomography (PET) $[20,21,31]$. The major characteristics of nanotargeted nuclear imaging modalities are listed in Table 3. In functional and molecular imaging, the in vivo radionuclide SPECT and PET imaging is the most sensitive with sub-nanomolar amounts of molecular probes and the highest tissue penetration range (Table 3 ).

For targeted radionuclide internal radiotherapy applications, high- and low-energy between $0.1-2.2 \mathrm{MeV}$ of $\beta$ emitters are ideal radioisotopes for the treatment of small to large clusters of tumor cells [14]. The maximum tissue penetration range $(1-10 \mathrm{~mm})[14,54]$ and cross-fire effects of $\beta$-particles with energy range between $0.1-2.2 \mathrm{MeV}$ can kill tumor cells in close proximity to neovasculature [14, 21, 54]. Alpha-emitters hold great promise as therapeutics for small cancer lesions and micrometastatic cancers due to the high-linear energy transfer (LET, $80 \mathrm{keV} / \mu \mathrm{m})$ and shortrange energy depositions with tissue penetration range of 50-100 $\mu \mathrm{m}$. Monoclonal antibody labeled with $\alpha$-emitters has been demonstrated to have high specific killing effects and minimal normal-tissue damage in a tumor-bearing animal model $[14,54]$. Auger electrons have an energy of $<30 \mathrm{keV}$ and subcellular pathlength of $2-12 \mu \mathrm{m}$. Thus, auger electron emitters can exert their radiotoxic effects on cells when they are internalized into the cytoplasm [55-57].

${ }^{123} \mathrm{I}$-ITdu-mediated nanoirradiation of DNA induces efficiently death in HL60 leukemia cells and in doxorubicin, $\beta$ - or $\gamma$-radiation-resistant cell lines has been examined. The experimental findings provide evidence that ultra-selective nanoirradiation of DNA through auger electron-carrying metabolic substrates offers an extremely effective strategy for inducing cell death and breaking resistance to more conventional types of irradiation or chemotherapy [58]. The schematic illustration of tumor tissue penetration range of radiation emitters for passively and actively nanotargeted radionuclide therapy is shown in Figure 1(b) [14].

\section{Passive Nanotargeting Delivery of Radionuclides for Tumor Nuclear Imaging and Radiotherapy}

Typically, nanotargeted radionuclides have a two-component architecture for passive targeting imaging and radiotherapeutics for example, a pegylated nanoliposome loaded with radionuclide payloads for nuclear imaging or radiotherapeutics $[20,21,31,59]$. The research and applications of selected passively nanotargeted nuclear imaging agents and radiotherapeutics are summarized in Table 4 . The history and progress of the preclinical development of liposometargeted treatments for cancer before 2000 were described in detail [60]. Optimal radiolabeled liposomes for tumor imaging have been established [61]. The clinical development of passively targeted liposomes as vehicles for targeted therapy of cancer have been summarized [62]. In addition, the potential areas for future development of liposometargeted strategies have also been considered [62].

Drug and radionuclides encapsulated within the liposome can occur in one of the three potential compartments: water-soluble agents are located in the central aqueous core of the liposome; lipid-soluble agents are carried in the liposome membrane; peptides and small proteins tend to bind to the interface between the lipid bilayer surface and the adjacent aqueous phase [60].

\subsection{Passive Nanotargeting Delivery of Radionuclides for Tumor Nuclear Imaging. The major characteristics of nanotargeted nuclear imaging modalities such as gamma imaging, SPECT and PET are listed in Table 3. Liposomes are self-assembling colloidal particles composed of a spherical bilayer of small phospholipid vesicles which is spontaneously formed when water is added to a dried lipid mixture [60]. Significant progress has been made in the use of liposome as a nanoparticle or nanocarrier for the delivery of radionuclides}


TABLE 1: Characteristics of potential radionuclides for nanotargeted tumor imaging $[20,21,28,29]$.

\begin{tabular}{lcccc}
\hline Radionuclide & Production & Emission type & Half-life & $E \max (\gamma),(\mathrm{keV})$ \\
\hline${ }^{131} \mathrm{I}$ & ${ }^{130} \mathrm{I}(\mathrm{n}, \gamma)^{131} \mathrm{Te}(\beta){ }^{131} \mathrm{I}$ & $\gamma(81.2 \%), \beta$ & 8.0 days & $284,364,637$ \\
${ }^{67} \mathrm{Ga}$ & ${ }^{68} \mathrm{Zn}(\mathrm{n}, \mathrm{p})^{67} \mathrm{Ga}$ & $\gamma$ & $78.3 \mathrm{~h}$ & $93,184,300,393$ \\
${ }^{111} \mathrm{In}$ & ${ }^{111} \mathrm{Cd}(\mathrm{p}, \mathrm{n})^{111} \mathrm{In}$ & Auger, $\gamma$ & $67.2 \mathrm{~h}$ & 171,245 \\
${ }^{123} \mathrm{I}$ & ${ }^{121} \mathrm{Sn}(\alpha, 2 \mathrm{n})^{123} \mathrm{I}$ & Auger, $\gamma$ & $13.2 \mathrm{~h}$ & 159 \\
${ }^{99 \mathrm{~m}} \mathrm{Tc}$ & ${ }^{99} \mathrm{Mo} / 99 \mathrm{~m} \mathrm{Tc}-$ generator & $\gamma$ & $6.0 \mathrm{~h}$ & 140 \\
${ }^{18} \mathrm{~F}$ & ${ }^{18} \mathrm{O}(\mathrm{p}, \mathrm{n})^{18} \mathrm{~F}$ & Positron & $1.83 \mathrm{~h}$ & $E_{\beta+} 635$ \\
${ }^{64} \mathrm{Cu}$ & ${ }^{64} \mathrm{Ni}(\mathrm{p}, \mathrm{n})^{64} \mathrm{Cu}$ & Positron & $12.7 \mathrm{~h}$ & $E_{\beta+} 656$ \\
${ }^{76} \mathrm{Br}$ & ${ }^{76} \mathrm{Se}(\mathrm{p}, \mathrm{n})^{76} \mathrm{Br}$ & Positron & $16.0 \mathrm{~h}$ & $E_{\beta+} 3941$ \\
${ }^{124} \mathrm{I}$ & ${ }^{124} \mathrm{Te}(\mathrm{p}, \mathrm{n})^{124} \mathrm{I}$ & Positron & $100.2 \mathrm{~h}$ & $E_{\beta+} 2134,1533$ \\
\hline
\end{tabular}

TABLE 2: Characteristics of potential radionuclides for tumor radiotherapy $[14,15,19-21,54,55]$.

\begin{tabular}{lcccccc}
\hline Radionuclide & Production & Emission type & Half-life & $\mathrm{E}_{\max }(\mathrm{MeV})$ & $\mathrm{R}_{\max }(\mathrm{mean})^{1}$ & Size of tumor cells $^{2}$ \\
\hline${ }^{186} \mathrm{Re}$ & ${ }^{185} \mathrm{Re}(\mathrm{n}, \gamma)^{186} \mathrm{Re}$ & $\beta, \gamma(9.4 \%)$ & $89.2 \mathrm{~h}$ & 1.07 & $5 \mathrm{~mm}(1.8 \mathrm{~mm})$ & Intermediate clusters \\
${ }^{188} \mathrm{Re}$ & ${ }^{188} \mathrm{~W} /{ }^{188} \mathrm{Re}$-generator & $\beta, \gamma(15.1 \%)$ & $17 \mathrm{~h}$ & 2.12 & $11 \mathrm{~mm}(2.4 \mathrm{~mm})$ & L clusters \\
${ }^{177} \mathrm{Lu}$ & ${ }^{176} \mathrm{Lu}(\mathrm{n}, \gamma)^{177} \mathrm{Lu}$ & $\beta$ & $161 \mathrm{~h}$ & 0.49 & $1.6 \mathrm{~mm}(0.67 \mathrm{~mm})$ & $\mathrm{S}$ clusters \\
${ }^{131} \mathrm{I}$ & ${ }^{131} \mathrm{Te}(\beta)^{131} \mathrm{I}$ & $\gamma(81.2 \%), \beta$ & $8 \mathrm{~d}$ & $0.28,0.36,0.64$ & $2.4 \mathrm{~mm}(0.8 \mathrm{~mm})$ & $\mathrm{S}$ clusters \\
${ }^{90} \mathrm{Y}$ & ${ }^{90} \mathrm{Sr} /{ }^{90} \mathrm{Y}$-generator & $\beta$ & $64.1 \mathrm{~h}$ & 2.28 & $12 \mathrm{~mm}(2.8 \mathrm{~mm})$ & L clusters \\
${ }^{67} \mathrm{Cu}$ & ${ }^{64} \mathrm{Ni}(\alpha, \mathrm{p})^{67} \mathrm{Cu}$ & $\beta$ & $2.6 \mathrm{~d}$ & 0.19 & $2.2 \mathrm{~mm}(0.7 \mathrm{~mm})$ & $\mathrm{S}$ clusters \\
${ }^{225} \mathrm{Ac}$ & ${ }^{225} \mathrm{Ra}$-generaor & $\alpha$ & $10 \mathrm{~d}$ & $5.83,5.79,5.79,5.73$ & $40-80 \mu \mathrm{m}$ & Single cells, S clusters \\
${ }^{111} \mathrm{In}$ & ${ }^{111} \mathrm{Cd}(\mathrm{p}, \mathrm{n})^{111} \mathrm{In}$ & Auger $\gamma$ & $67 \mathrm{~h}$ & 0.42 & $2-500 \mathrm{~nm}$ & Single cells \\
\hline
\end{tabular}

L: large; S: small.

${ }^{1}$ Radiation tumor tissue penetration maximum and mean range.

${ }^{2}$ Small, intermediate and large clusters correspond approximately to the intervals $10^{4}-10^{6}, 10^{6}-10^{8}$, and $10^{8}-10^{10}$ tumor cells per clusters, respectively [54].

for imaging. Selected research and applications of passively nanotargeted cancer nuclear imaging agents and radiotherapeutics are summarized in Table 4.

Delivery of ${ }^{99 \mathrm{~m} T c},{ }^{111} \mathrm{In}$, and ${ }^{67} \mathrm{Ga}$ radionuclides by liposomes for gamma-imaging and monitoring drug treatment have been reviewed and reported for preclinical and clinical studies [28, 29, 60-63]. A systemic study of optimal liposome formulation and encapsulation of radionuclides was also reported $[60,61]$. The biodistribution, pharmacokinetics, and nuclear imaging of ${ }^{111}$ In-DTPA-labeled pegylated liposome were studied in patients with advanced local cancer [53]. Effective targeting of solid tumors of breast $(5.3 \pm 2.6$ $\% \mathrm{ID} / \mathrm{kg}$ for a tumor volume of $234.7 \pm 101.4 \mathrm{~cm}^{3}$ ), head and neck (highest uptake of $33.0 \pm 15.8 \% \mathrm{ID} / \mathrm{kg}$ for a tumor volume of $\left.36.2 \pm 18.0 \mathrm{~cm}^{3}\right)$, lung $(18.3 \pm 5.7 \% \mathrm{ID} / \mathrm{kg}$ for a tumor volume of $114.5 \pm 42.0 \mathrm{~cm}^{3}$ ), brain, and cervix was also observed with gamma camera and SPECT imaging [53]. Conventional ${ }^{111}$ In-based liposome (Vescan) preclinical and clinical performance and evaluation of lessons learned from the formulation and process development has been discussed and summarized [64]. In recent years, clinical studies using radiolabeled liposomes for tumor diagnostic imaging of cancer and inflammation from 1979 to 2001 have been reported [65]. A novel amphiphilic probes for ${ }^{18} \mathrm{~F}-$ radiolabeling performed liposomes and determination of liposomal trafficking by PET was developed [66]. Liposomes encapsulating positron emitter ${ }^{18} \mathrm{~F}$ and ${ }^{64} \mathrm{Cu}$ were applicable for diagnostic imaging and real-time liposomal tracking in vivo [66-69].
Wang et al. demonstrated an intravenous administration of ${ }^{111}$ In-liposome by conjugating ${ }^{111} \mathrm{In}$-oxine to DTPA/PEGliposome followed by whole-body scintigraphy. Images revealed that the tumor clearly accumulated ${ }^{111} \mathrm{In}$-liposome up to $48 \mathrm{~h}$ postinjection (p.i.) [70]. In addition to the diagnostic imaging of ${ }^{111}$ In-liposome, Lee et al. demonstrated the bifunctional imaging and bimodality therapeutic efficacy of radiochemo-therapeutics of ${ }^{111} \mathrm{In}-\mathrm{VNB}$-liposomes in HT-29/luc mouse xenografts [71]. Table 4 lists some of the selected passively nanotargeted liposomes delivery of radionuclides for nuclear imaging. The gamma scintigraphy and SPECT/CT image passively nanotargeted radionuclides of ${ }^{111} \mathrm{In}$-liposome (Figure 2(a)) [70], ${ }^{188} \mathrm{Re}$-liposome, and ${ }^{188}$ Re-DXR-liposome (Figure 2(c)) [70, 72] targeting on CT26 tumor bearing in $\mathrm{BALB} / \mathrm{c}$ mice animal model through the EPR localization effect were illustrated.

3.2. Passive Nanotargeting Delivery of Radionuclides for Tumor Radiotherapy. An analytical dosimetry study for the use of ${ }^{131} \mathrm{I},{ }^{90} \mathrm{Y},{ }^{188} \mathrm{Re}$, and ${ }^{67} \mathrm{Cu}$ radionuclide-labeled liposome for internal radiotherapy has been reported, and the analysis suggested that the optimal liposome system for radiotherapy differs from chemotherapy delivery [74]. In previous clinical targeting tumor imaging studies [53], the results of the effective targeting of solid tumors in patients with advanced local cancers by radiolabeled pegylated liposomes support the possible delivery of $\beta$-emitting radionuclideloaded pegylated liposome for the treatment of solid tumors, particularly those liposomes in head and neck patients. 
TABLE 3: Characteristics of nanotargeted nuclear imaging modalities [20, 21].

\begin{tabular}{|c|c|c|c|c|c|c|}
\hline Modality & Image probe (Amount of probe) & Type of radiation & Sensitivity & Spatial Resolution & Depth & Nanoparticle design \\
\hline \multirow[t]{4}{*}{ SPECT } & ${ }^{99 \mathrm{~m}} \mathrm{Tc},{ }^{111} \mathrm{In}$ etc & $\gamma$-ray & $10^{-10}-10^{-11}(\mathrm{pM})$ & $0.5-1 \mathrm{~mm}$ & No limit & Surface \\
\hline & & & & & & $\begin{array}{l}\text { Bio-conjugation } \\
\text { or after loading }\end{array}$ \\
\hline & loaded or labeled & & & & & \\
\hline & nanocarriers (ng) & & & & & \\
\hline \multirow[t]{4}{*}{ PET } & ${ }^{18} \mathrm{~F},{ }^{64} \mathrm{Cu}$ etc & Positron & $10^{-11}-10^{-12}(\mathrm{pM})$ & $1-2 \mathrm{~mm}$ & No limit & Surface \\
\hline & & & & & & $\begin{array}{l}\text { Bio-conjugation } \\
\text { or after loading }\end{array}$ \\
\hline & loaded or labeled & High energy & & & & \\
\hline & nanocarriers (ng) & $\gamma$-ray & & & & \\
\hline
\end{tabular}

SPECT: single photon emission computed tomography; PET: positron emission tomography.

Bao et al. have developed a method of labeling liposomes with radionuclides using N,N-bis(2-Mercaptoethyl)- $\mathrm{N}^{\prime} \mathrm{N}^{\prime}$ diethylethylenediamine (BMEDA) to after-load ${ }^{99 \mathrm{~m}} \mathrm{Tc}$ or ${ }^{186} \mathrm{Re}$ into liposomes $[65,75,76]$. In addition to therapy via intravenous administration, the intratumoral and intraoperational therapies were also investigated for the potential use of ${ }^{186} \mathrm{Re}$-liposomes [77-79]. High-resolution SPECT/CT images revealed the intratumoral distribution of therapeutic liposomes; this result indicated the potential use of ${ }^{186} \mathrm{Re}$-liposomes for intratumoral therapy [78, 79]. Intraoperative passive nanotargeted ${ }^{186} \mathrm{Re}$-liposome therapy showed an excellent tumor suppression and minimal side-effect profile in the head and neck squamous cell carcinoma xenograft positive surgical margin model [78]. Biodistribution, pharmacokinetics, and nuclear imaging of passively nanotargeted radio-therapeutics of ${ }^{111} \mathrm{In} /{ }^{188} \mathrm{Re}-$ liposome on C26 and HT-29 colon carcinoma-bearing animal models have been studied by our group [70, 72, 80]. ${ }^{111}$ In has a $\gamma$-ray with $171 \mathrm{keV}$ energy for nuclear imaging and an auger electron with $0.42 \mathrm{MeV}$ energy in the nm tissue penetration range with specific single tumor cell or small tumor cluster killing effect (Table 2 and Figure 1(b)). ${ }^{188} \mathrm{Re}$ has a $\gamma$-ray with $155 \mathrm{keV}$ energy for nuclear imaging and a high-energy beta emitter with $2.12 \mathrm{MeV}$ energy for killing nonspecific large tumor clusters. Both radionuclides can be used in bifunctional nuclear imaging and internal radiotherapeutic applications. The long-circulating pegylated liposomes radiolabeled with ${ }^{188} \mathrm{Re}\left({ }^{188} \mathrm{Re}\right.$-liposomes $)$ showed a higher uptake in the tumor as compared with ${ }^{188} \mathrm{Re}-$ BMEDA alone. Passively nanotargeted ${ }^{188} \mathrm{Re}$-liposomes were found to have a 7.1-fold higher tumor-to-muscle ratio as compared with intravenously administered unencapsulated ${ }^{188}$ Re-BMEDA in a C26 murine colon carcinoma solid tumor animal model [72]. Improvement of biodistribution and therapeutic index via increase of polyethylene glycol(PEG) from $0.9 \%$ to $6 \%$ on passively nanotargeted ${ }^{111}$ In-liposome in an HT-29/luc xenografted mouse model was observed [81]. Targeted $\alpha$-particle emitters are promising therapeutics for micrometastatic tumors. Enhanced loading of ${ }^{225} \mathrm{Ac}$ and retention of three $\alpha$-particle-emitting daughters of ${ }^{225} \mathrm{Ac}$ by passively targeted liposomes have been demonstrated [82-84].
Boron neutron capture therapy (BNCT) is a binary approach to cancer therapy involving the nuclear reaction that occurs when ${ }^{10} \mathrm{~B}$ is irradiated with thermal neutrons to yield high LET of $\alpha$-particles and lithium nuclei $(2.4 \mathrm{MeV})$. These particles have a short range $(<10 \mu \mathrm{m})$ and deposit their energy within single cells. The efficacy and successful treatment of tumors by BNCT depend on the selective delivery of relatively high amounts of ${ }^{10} \mathrm{~B}$ to tumors. There are three important parameters for development of boron compounds: (i) achieving tumor concentration in the range of $20-35 \mu \mathrm{g}{ }^{10} \mathrm{~B} / \mathrm{g}$, (ii) reaching a tumor/normal tissue ratio greater than 3-5, and (iii) illustrating sufficiently low toxicity. Application of passive stealth liposome-entrapped ${ }^{10} \mathrm{~B}$ delivery systems has been studied for BNCT in animal models [85, 86]. The results of the study on ${ }^{10} \mathrm{~B}-\mathrm{PEG}$-liposome through intravenous injection suggested that passively targeted delivery of sodium mercaptoundecahydrododecaborate $\left({ }^{10} \mathrm{BSH}\right)$ can increase the retention of ${ }^{10} \mathrm{~B}$ by tumor cells, causing the suppression of tumor growth in vivo for BNCT [86]. A high level of ${ }^{10} \mathrm{~B}$ concentration (22 ppm) was observed in tumor tissues at $24 \mathrm{~h}$ after the administration of boron liposomes, and the tumor was significantly suppressed [85].

3.3. Passive Nanotargeting Codelivery of Radionuclides and Chemotherapeutics for Tumor Radiochemotherapeutics. Concomitant chemotherapy and radiotherapy has been found to improve treatment outcome in a range of solid tumors. Pegylated liposome-encapsulated doxorubicin and cisplatin have shown to be the potential target drugs to tumors, showing increase in therapeutic efficacy and reduction in toxicity [87]. Trimodal cancer therapy combining antiangiogenesis, chemotherapy, and radiotherapy achieves beneficial effects when used as a clinical antitumor strategy [88]. Image-guided and passive nanocarrier-based polymeric nanomedicine for radiotherapy holds significant potential for improving the treatment of advanced solid tumors [89]. Biodistribution, pharmacokinetics, nuclear imaging, and therapeutic efficacies were investigated for nanotargeted bifunctional co-delivery radiochemotherapeutics of ${ }^{111} \mathrm{In} /$ ${ }^{188} \mathrm{Re}$-(vinorelbine/doxorubicin, VNB/DXR)-liposomes on colorectal carcinoma of HT-29 and C26 tumor and ascitesbearing animal models $[71,73,90-93]$. In addition to the 
diagnostic imaging of ${ }^{111} \mathrm{In} /{ }^{188}$ Re-liposome, the additive therapeutic efficacy was observed for the comparative co-delivery radiochemo-therapeutics of specific-killing auger electron emitters of ${ }^{111} \mathrm{In}$-(VNB)-liposomes on HT29/luc mouse xenografts [71, 92]. ${ }^{188}$ Re-DXR-liposomes could provide a beneficial and promising strategy for the co-delivery of passively nanotargeted bimodality radiochemotherapeutics in the treatment of solid tumor and ascites [73, 91]. The experimental results pointed to the potential benefit of the co-delivery of nanoliposome radiochemotherapeutics for adjuvant cancer treatment in oncology applications [73]. Evaluation of pharmacokinetics of ${ }^{111} \mathrm{In}$-VNB-liposome on C26/tk-luc after intraperitoneal (i.p.) and intravenous (i.v.) administration in a tumor/ascites mouse model was studied and compared, the results indicated that the i.p. was a better approach than i.v. injection in the treatment of i.p. malignant tumor/ascites model [93]. Previous theoretical dosimetry studies have addressed the potential use of therapeutic nanoliposomes for the treatment of tumors via intravenous injection [74, 94, 95]. The comparative dosimetric evaluation of nanotargeted ${ }^{188} \mathrm{Re}-$ (DXR)-liposome derived from the biodistribution indicated that the delivery radiation doses were safe and feasible for further clinical translation research from bench to bedside [90]. The results for major organs doses for the ${ }^{188} \mathrm{Re}-$ (DXR)-liposome revealed that similar doses were received by spleen and liver, but a lower dose was given to kidney, compared with ${ }^{111}$ In-DTPA-octreotide therapy. Lower doses were also received by total body and liver, compared with ${ }^{111}$ In-DTPA-human epidermal growth factor (hEGF) radiotherapeutics (0.19 and $0.76 \mathrm{mGy} / \mathrm{MBq}$, respectively). The absorbed doses for spleen, liver, kidney, and red marrow in these studies are much lower than those from ${ }^{90} \mathrm{Y}$ 1,4,7,10-tetraazacyclododecane- $\mathrm{N}, \mathrm{N}^{\prime}, \mathrm{N}^{\prime \prime}, \mathrm{N}^{\prime \prime \prime}$-tetraacetic acid tyrosine octreotide (DOTATOC) therapy [90]. Table 4 lists the selected passively nanotargeted nuclear imaging and radiotherapeutic applications. The tumor growth inhibition and therapeutic efficacy studies of passively nanotargeted radionuclides of ${ }^{111} \mathrm{In}$-(VNB)-liposome on HT-29/luc tumor bearing in SCID mice animal model (Figure 2(b)) [71], and ${ }^{188} \mathrm{Re}$-(DXR)-liposome on CT-26 solid tumor on BALB/c mice animal model were illustrated (Figure 2(d)) [71, 90]. The synergistic therapeutic efficacy was also demonstrated in the co-delivery of nanotargeted radiochemo-therapeutics of ${ }^{188}$ Re-DXR-liposome [73].

\section{Active Nanotargeting Delivery of Radionuclides for Tumor Nuclear Imaging and Radiotherapy}

Typically, nanotargeted radionuclides have a threecomponent architecture for active targeting therapeutics, such as pegylated nanoliposome surface bioconjugated with bioactive antibody or peptide, and encapsulated or bioconjugated with therapeutic radionuclide payloads for tumor-targeted nuclear imaging or radiotherapeutics $[20,21]$. In addition, tumor-specific receptor targeting of nanocarriers could provide for high-antitumor therapeutic activity and imaging efficacy with low adverse side effects on healthy organs for practically any type of anticancer/ imaging drug delivery systems $[22,23,41,42]$. The selected research and applications of actively nanotargeted tumor nuclear imaging and radiotherapeutics are summarized in Table 5.

\subsection{Active Nanotargeting Delivery of Radionuclides for Tumor} Nuclear Imaging. The ability to modify the surface of nanocarriers permits the improvement in the pharmacokinetics, bioavailability, toxicity, and customization of nanocarrier formulations for particular actively nanotargeted tumor imaging [96]. Enhanced tumor accumulation and visualization by $\gamma$-scintigraphy with ${ }^{111} \mathrm{In}$-labeled nucleosome-specific monoclonal antibody $2 \mathrm{C} 5$ bioconjugated immunoliposome has been studied, and the results indicated better and faster imaging in various tumorbearing mice [45-47]. Pharmaceutical lipid-based nanocarriers modified with $\mathrm{mAb} 2 \mathrm{C} 5$ could represent a new system for tumor-specific delivery of soluble, insoluble, and radionuclide pharmaceuticals [45]. $\alpha_{\mathrm{v}} \beta_{3}$-Integrin-targeted ${ }^{111}$ In perfluorocarbon nanoparticles have been developed and studied for the detection of rabbit $\mathrm{Vx}-2$ tumor angiogenesis. The circulatory half-life was estimated to be $5 \mathrm{~h}$. The mean tumor uptake was 4-fold higher than the nontargeted control. The specificity activity $(\mathrm{mCi} / \mathrm{ml})\left({ }^{111} \mathrm{In} / \mathrm{NP}\right)$ of ${ }^{111} \mathrm{In}$ to nanoparticle (NP) may affect the tumor-to-muscle ratio in patients. The tumor-to-muscle uptake ratios for the nanotargeted ${ }^{111} \mathrm{In} / \mathrm{NP}=10$ to ${ }^{111} \mathrm{In} / \mathrm{NP}=1$ were $6.3 \pm 0.2$ to $5.1 \pm 0.1$, respectively. The data suggest that $\alpha_{\mathrm{v}} \beta_{3}$-targeted ${ }^{111}$ In perfluorocarbon nanoparticles may provide a clinically useful tool for detecting angiogenesis in nascent tumors [48]. ${ }^{111}$ In radiolabeled soluble functionalized multifunctional drug delivery platforms of active targeting with rituximab monoclonal antibody bioconjugated on single-wall carbon nanotubes have been developed, and the selectivity of targeting disseminated human lymphoma was evaluated in vitro and in vivo [40]. The results of the ability to target tumor specifically with prototype-radiolabeled or fluorescent-labeled, antibody-appended carbon nanotube constructs are encouraging and suggest further investigation of carbon nanotubes as a novel radionuclide delivery platform [40].

The development of a dual-function PET/near-infrared fluorescence (NIRF) molecular probe for the accurate assessment of pharmacokinetics and tumor-targeting efficacy of U87MG human glioblastoma tumor-bearing mice has been reported [37]. The amine-functionalized surface of quantum dot (QD) bioconjugated with arginine-glycine-aspartic acid (RGD) peptides and 1,4,7,10-tetraazacyclododecane1,4,7,10-tetraacetic acid (DOTA) for ${ }^{64} \mathrm{Cu}$ radiolabeled ${ }^{64} \mathrm{Cu}$-DOTA-QD-RGD nanoconstructs with 90 RGD per QD to target angiogenesis for application in integrin$\alpha_{\mathrm{v}} \beta_{3}$ PET/NIRF imaging was also illustrated [37]. This dual-function nuclear/optical in vivo molecular probe revealed a quantitative targeting ability in deep tumor lesions [37]. Dual modality optical and PET imaging of vascular endothelial growth factor receptor (VEGFR) on 


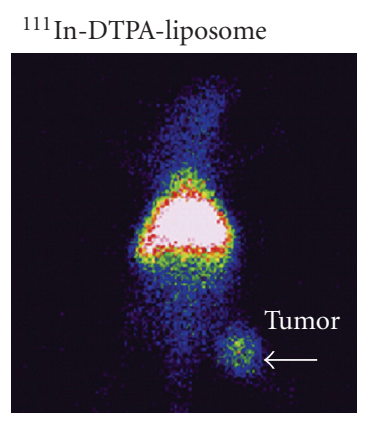

$24 \mathrm{~h}$

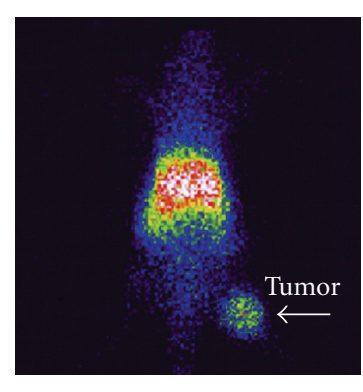

$48 \mathrm{~h}$

(a)

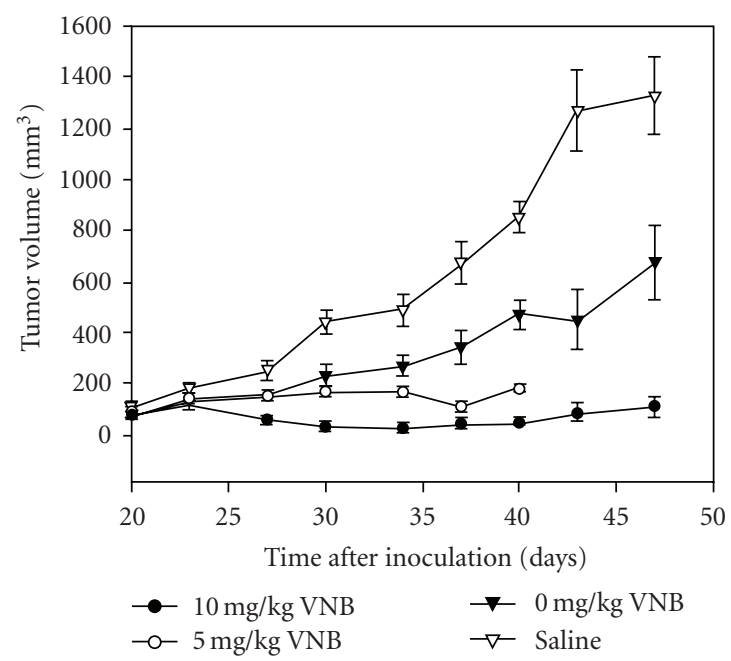

(b)

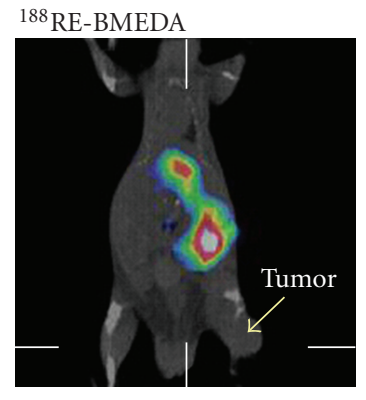

$1 \mathrm{~h}$

${ }^{188}$ RE-BMEDA-liposome

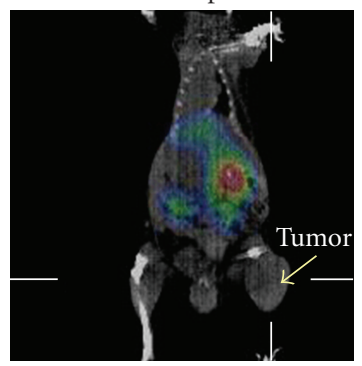

$1 \mathrm{~h}$

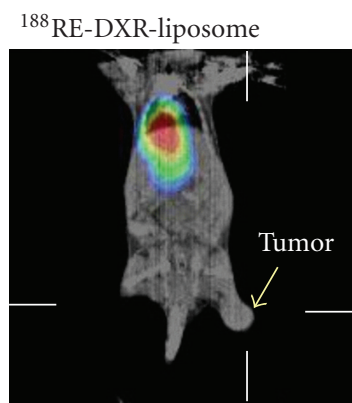

$1 \mathrm{~h}$

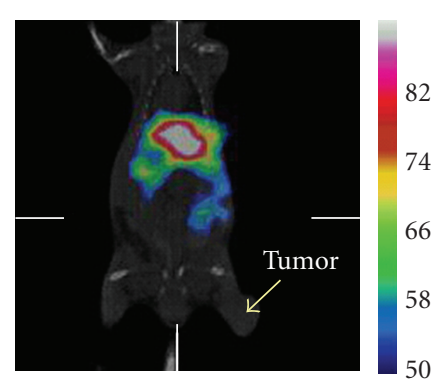

$4 \mathrm{~h}$

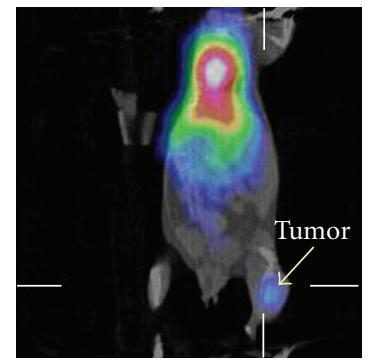

$4 \mathrm{~h}$
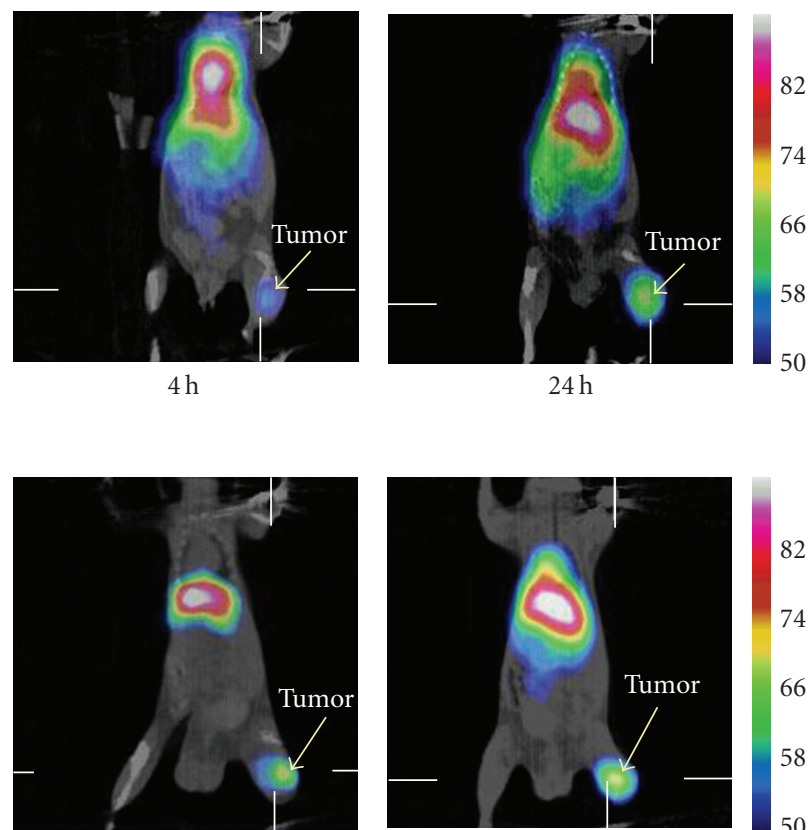

$4 \mathrm{~h}$

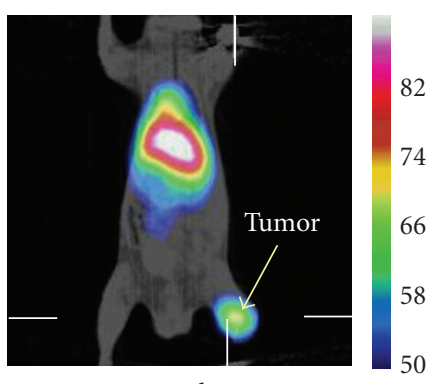

$24 \mathrm{~h}$

(c)

Figure 2: Continued. 

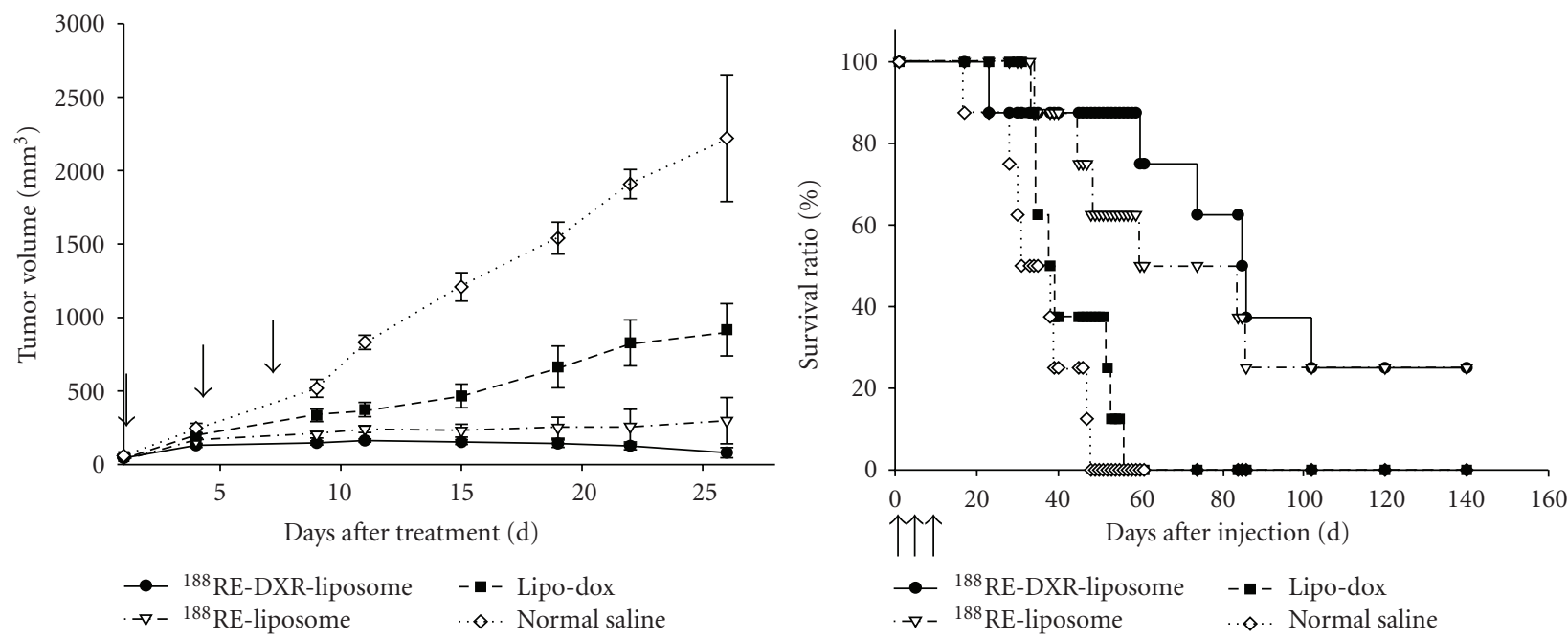

(d)

Figure 2: (a) Gamma scintigraphy of BALB/c mice bearing CT-26 tumor animal model at $24 \mathrm{hr}$ and $48 \mathrm{hr}$ after intravenous injection of passively nanotargeted radionuclides of ${ }^{111}$ In-DTPA-liposome (reprinted with permission from reference [70]). (b) Tumor growth inhibition with passively nanotargeted radionuclides of ${ }^{111} \mathrm{In}$-(VNB)-liposome on HT-29/luc tumor bearing in SCID mice animal model (reprinted with permission from reference [71]). (c) MicroSPECT/CT images of passively nanotargeted radionuclides of ${ }^{188} \mathrm{Re}-\mathrm{liposome}$ and ${ }^{188} \mathrm{Re}-$ DXR-liposome targeting CT-26 bearing in BALB/c mice animal model at $1 \mathrm{~h}, 4 \mathrm{~h}, 24 \mathrm{~h}$, and compare with the control (reprinted with permission from reference [72]). (d) Therapeutic efficacy of tumor volume change and survival ratio for CT-26 tumor-bearing BALB/c mice after intravenous administration of passively nanotargeted radionuclides of ${ }^{188} \mathrm{Re}$-(DXR)-liposome were illustrated. (reprinted with permission from reference [73]).

tumor vasculature using QDs of ${ }^{64} \mathrm{Cu}$ radiolabeled ${ }^{64} \mathrm{Cu}$ DOTA-QD-VEGF was also investigated [38]. The U87MG tumor uptake of active nanotargeted ${ }^{64} \mathrm{Cu}-\mathrm{DOTA}-\mathrm{QD}-\mathrm{VEGF}$ $(1.52 \pm 0.6 \%$ injected dose/gram $(\% \mathrm{ID} / \mathrm{g}), 2.81 \pm 0.3$ $\% \mathrm{ID} / \mathrm{g}, 3.84 \pm 0.4 \% \mathrm{ID} / \mathrm{g}$, and $4.16 \pm 0.5 \% \mathrm{ID} / \mathrm{g}$ at 1,4 , 16 , and $24 \mathrm{~h}$, respectively, postinjection) was one percentage injected dose per gram $(\% \mathrm{ID} / \mathrm{g})$ higher than that of passively targeted ${ }^{64} \mathrm{Cu}$-DOTA-QD [38]. ${ }^{18} \mathrm{~F}$-labeled phospholipids quantum dot micelles for in vivo PET and optical fluorescence imaging from cells to whole body have been designed and studied [39]. Development of a bifunctional nanotargeted iron oxide (IO) molecular probe for PET and magnetic resonance imaging (MRI) of tumor integrin- $\alpha_{\mathrm{v}} \beta_{3}$ expression was reported; this bifunctional ${ }^{64} \mathrm{Cu}-\mathrm{DOTA}-\mathrm{IO}$ RGD nanotargeted molecular imaging approach may allow for earlier tumor detection and may provide insight into the molecular mechanisms of cancer $[32,33]$. The synthesis and in vivo characterization of an ${ }^{18} \mathrm{~F}$-labeled trimodal (MRI/PET-CT/optical) iron oxide(IO) for tumor imaging, the facile conjugation chemistry, provides a simple platform for rapid and efficient IO labeling [34]. Tumor targeting angiogenesis and comparison of ${ }^{99 \mathrm{~m}} \mathrm{Tc}$-labeled peptide and ${ }^{99 \mathrm{~m}}$ Tc-labeled polymer-peptide nanocarrier conjugates were investigated [35]. Specific targeting of the $\alpha_{v} \beta_{3}$ integrin and nonspecific vascular permeability are both significant, but active specific targeting is more important than EPR of the carrier molecule. Nonspecific vascular permeability appears to be a major factor in reducing tumor-to-normal tissue localization ratio for the peptide molecules [35]. Biodegradable ${ }^{76} \mathrm{Br}$-labeled dendritic bioconjugated RGD bifunctional nanoprobes for the noninvasive PET imaging of angiogenesis was reported [36]. Figure 3 demonstrated the in vivo actively nanotargeted radionuclides of ${ }^{64} \mathrm{Cu}-\mathrm{DOTA}-\mathrm{QD}$ RGD for dual-function PET and near-infrared fluorescence (NIR) imaging of a U87MG tumor vasculature mice animal model [37].

4.2. Active Nanotargeting Delivery of Radionuclides for Tumor Radiotherapeutics. Significant radiation-induced antisensemediated cytotoxicity of tumor cells in vitro was achieved using an auger electron-emitting antisense antiR $1 \alpha$ messenger RNA antisense morpholino (MORF) oligomer administered as a member of a three-component streptavidindelivery nanoparticle ( ${ }^{111} \mathrm{In}-\mathrm{MORF} /$ tat/trastuzumab) [50]. Targeted angiogenesis $\alpha_{v} \beta_{3}$ and VEGFR2 with threecomponent actively nanotargeted radionuclides of ${ }^{90} \mathrm{Y}$ liposome-IA (integrin antagonist) and ${ }^{90} \mathrm{Y}$-liposome-antiFlk-1 (mAb) have been reported in murine melanoma K1735-M2 and colon CT26 animal models [49]. The results demonstrated that ${ }^{90}$ Y-liposome-anti-Flk-1 (mAb) was significantly more efficacious than conventional radioimmunotherapy in the mouse melanoma model [49].

Enhanced targeting, loading and retention of ${ }^{225} \mathrm{Ac}$, and three $\alpha$-particle-emitting daughters of ${ }^{225} \mathrm{Ac}$ by actively nanotargeted immunoliposomes have also been illustrated [82-84]. The efficacy and successful treatment of tumors by BNCT depend on the selective delivery of relatively high amounts of ${ }^{10} \mathrm{~B}$ to tumors. Application of active folatereceptor targeted PAMAM-dendrimers and active cetuximab immunoliposome-entrapped ${ }^{10} \mathrm{~B}$ delivery systems has been 
TABLE 4: Selected passively nanotargeted tumor nuclear imaging and radiotherapeutic applications.

\begin{tabular}{|c|c|c|c|c|}
\hline Nanoparticles & Radionuclides & Imaging or Radiotherapeutics & Applications & Reference \\
\hline Liposomes & ${ }^{99 \mathrm{~m}} \mathrm{Tc},{ }^{111} \mathrm{In},{ }^{67} \mathrm{Ga},{ }^{99 \mathrm{~m}} \mathrm{Tc}$ & Gamma imaging & $\begin{array}{l}\text { Multitude diagnostics of tumor, } \\
\text { infection, Inflammation, and } \\
\text { lymphoscintigraphy }\end{array}$ & {$[28,29,60-62]$} \\
\hline Liposomes & ${ }^{111}$ In & Gamma/SPECT imaging & $\begin{array}{l}\text { Clinical biodistribution, PK and imaging } \\
\text { studies of breast, head and neck, glioma } \\
\text { and lung cancer patients }\end{array}$ & {$[53,62]$} \\
\hline Liposomes & ${ }^{18} \mathrm{~F}$ & PET imaging & $\begin{array}{l}\text { Liposomal tracking in vivo with } \\
{ }^{18} \mathrm{~F} \text {-limposome-PET imaging }\end{array}$ & {$[66-68]$} \\
\hline Liposomes & ${ }^{111} \mathrm{In},{ }^{177} \mathrm{Lu}$ & Gamma/SPECT imaging & $\begin{array}{l}\text { Gamma imaging of tumor targeting for } \\
\text { C26 and HT29/luc animal models }\end{array}$ & {$[70,71]$} \\
\hline Liposomes & ${ }^{64} \mathrm{Cu}$ & PET imaging & $\begin{array}{l}\text { Passive targeted delivery and imaging } \\
\text { with bioconjugated }{ }^{64} \mathrm{Cu}-\mathrm{BAT}- \\
\text { PEG-liposome }\end{array}$ & {$[69]$} \\
\hline Liposomes & ${ }^{131} \mathrm{I},{ }^{90} \mathrm{Y},{ }^{188} \mathrm{Re},{ }^{67} \mathrm{Cu}$ & Radiotherapeutics & $\begin{array}{l}\text { An analytical dosimetry study for the use } \\
\text { of radionuclide-liposome conjugates in } \\
\text { internal radiotherapy }\end{array}$ & {$[74]$} \\
\hline Liposomes & ${ }^{186} \mathrm{Re}$ & Radiotherapeutics & $\begin{array}{l}\text { Intraoperative }{ }^{186} \text { Re-liposome } \\
\text { radionuclide therapy in a head and neck } \\
\text { squanous cell carcinoma xenograft } \\
\text { positive surgical margin model }\end{array}$ & {$[78]$} \\
\hline Liposomes & ${ }^{111} \mathrm{In},{ }^{188} \mathrm{Re}$ & Radiotherapeutics & $\begin{array}{l}\text { Imaging, biodistribution, } \\
\text { pharmacokinetics, and therapeutic } \\
\text { efficacy studies of }{ }^{111} \mathrm{In} /{ }^{188} \text { Re-liposome } \\
\text { on C26 and HT- } 29 \text { tumor-bearing animal } \\
\text { models }\end{array}$ & {$[70,72,80,81]$} \\
\hline Liposomess & ${ }^{225} \mathrm{Ac}$ & Radiotherapeutics & $\begin{array}{l}\text { Targeted } \alpha \text {-particles emitters of } \\
{ }^{225} \text { Ac-generators encapsulated in } \\
\text { liposomes as therapeutic agents for } \\
\text { micrometastases cancer }\end{array}$ & {$[82-84]$} \\
\hline Liposomes & ${ }^{10} \mathrm{~B}$ & Radiotherapeutics & $\begin{array}{l}{ }^{10} \mathrm{~B} \text {-liposomes nanotargeted therapeutics } \\
\text { for boron neutron capture therapy } \\
(\mathrm{BNCT})\end{array}$ & {$[85,86]$} \\
\hline Liposomes & ${ }^{111} \mathrm{In},{ }^{188} \mathrm{Re}$ & Radiochemo-therapeutics & $\begin{array}{l}\text { Imaging, biodistribution, } \\
\text { pharmacokinetics, therapeutic efficacy, } \\
\text { and dosimetry studies of } \\
{ }^{111} \mathrm{In} /{ }^{188} \mathrm{Re}-\mathrm{VNB} / \mathrm{DXR}-\mathrm{lip} \text { osome on C26 } \\
\text { and HT-29 tumor/ascites-bearing animal } \\
\text { models }\end{array}$ & {$[71,73,81,90-93]$} \\
\hline
\end{tabular}

mAb: monoclonal antibody, CNT: carbon nanotube, QD: quantum dots, IO: iron oxide.

studied for BNCT applications in animal models [51, 52]. Major challenges that have to be addressed by drug-delivery nanocarriers in cancer therapy are the low drug bioavailability of therapeutics within cancer cells and the high toxicities at normal organs due to the low tumor targeting or localization. The combination of molecular targeting of bioconjugated nanoparticles or immunoliposomes can provide targeted cell internalization and intracellular drug release to improve anticancer therapeutic efficacy and to reduce toxicity [97]. Active receptor nanotargeted polymers, dendrimers, and liposomes employed for targeting to tumorspecific receptors can prevent serious adverse side effects on healthy organs. In addition, the internalization and intracellular distribution of nanocarriers in cancer cells indicated that tumor-specific receptor active targeting of nanocarriers could provide high antitumor therapeutic activity and imaging efficacy with low adverse side effects on normal tissues [41].

4.3. Nanoparticles for Concurrent Multimodality Nuclear Imaging and Radiotherapeutics. Nanoparticles have advantages for cancer nuclear imaging and radiotherapy. The ultimate goal in the design and preparation of multifunctional and multimodality nanoparticles in drug delivery is the creation of combined diagnostics and therapeutics (or theragnostics) and combined radiochemo-therapeutics for the targeted diagnosis and treatment of cancer [44, 97]. Recent advances in the field of nanotechnology and nanomedicine indeed offer the promise of better diagnostic and therapeutic options. Newer generation of nanoparticles has been designed and synthesized to target specific types of cell and molecule via affinity ligands from phage or 
TABLE 5: Selected actively nanotargeted tumor nuclear imaging and radiotherapeutic applications.

\begin{tabular}{|c|c|c|c|c|}
\hline Nanoparticles & Radionuclides & $\begin{array}{l}\text { Imaging or } \\
\text { Radiotherapeutics }\end{array}$ & Applications & Reference \\
\hline Immunoliposome & ${ }^{111}$ In & $\begin{array}{l}\text { Gamma imaging and } \\
\text { therapeutics }\end{array}$ & $\begin{array}{l}{ }^{111} \text { In-liposome-2C } 5(\mathrm{mAb}) \\
\text { nucleosome-specific monoclonal } 2 \mathrm{C} 5 \text { targeting } \\
\text { delivery vehicles for tumor visualization of } \\
\text { murine lewis lung carcinoma and human } \\
\text { HT-29 tumors }\end{array}$ & [45-47] \\
\hline $\begin{array}{l}\text { Perfluorocarbon } \\
\text { nanoparticles }\end{array}$ & ${ }^{111}$ In & Gamma imaging & $\begin{array}{l}\text { Imaging of targeted tumor angiogenesis of } \\
\alpha_{\mathrm{v}} \beta_{3} \text {-integrin in } \mathrm{Vx}-2 \text { rabbit tumors }\end{array}$ & {$[48]$} \\
\hline Carbon nanotubes & ${ }^{111}$ In & Gamma or SPECT imaging & $\begin{array}{l}\text { Multifunctional targeted delivery and imaging } \\
\text { with. functionalized and bioconjugated } \\
{ }^{111} \text { In-DOTA-CNT-Rituximab nanoconstructs }\end{array}$ & {$[40]$} \\
\hline Quantum dots & ${ }^{64} \mathrm{Cu}$ & $\begin{array}{l}\text { Bifunctional PET/NIRF } \\
\text { imaging }\end{array}$ & $\begin{array}{l}\text { Dual-functional targeted delivery with amine } \\
\text { functionalized }{ }^{64} \mathrm{Cu} \text {-DOTA-QD-RGD for } \\
\text { tumor angiogenesis PET/NIRF imaging }\end{array}$ & {$[37]$} \\
\hline Quantum dots & ${ }^{64} \mathrm{Cu}$ & $\begin{array}{l}\text { Bifunctional PET/NIRF } \\
\text { imaging }\end{array}$ & $\begin{array}{l}\text { Dual-functional targeted delivery with amine } \\
\text { functionalized }{ }^{64} \mathrm{Cu}-\mathrm{DOTA}-\mathrm{QD}-\mathrm{VEGF} \text { for } \\
\text { tumor angiogenesis PET/NIRF imaging }\end{array}$ & {$[38]$} \\
\hline Quantum dots & ${ }^{18} \mathrm{~F}$ & $\begin{array}{l}\text { Bifunctional PET/optical } \\
\text { imaging }\end{array}$ & $\begin{array}{l}{ }^{18} \mathrm{~F} \text { labeled phospholipids quantum dot } \\
\text { micelles for in vivo multimodal imaging }\end{array}$ & {$[39]$} \\
\hline Iron oxide & ${ }^{64} \mathrm{Cu}$ & $\begin{array}{l}\text { Bifunctional PET/MRI } \\
\text { imaging }\end{array}$ & $\begin{array}{l}\text { PET/MRI dual-modality tumor angiogenesis } \\
\text { imaging with }{ }^{64} \mathrm{Cu}-\mathrm{DOTA}-\mathrm{IO}-\mathrm{RGD} \\
\text { nanoconstructs }\end{array}$ & {$[32,33]$} \\
\hline Iron oxide & ${ }^{18} \mathrm{~F}$ & $\begin{array}{l}\text { Trimodel } \\
\text { MRI/PET-CT/optical } \\
\text { imaging }\end{array}$ & $\begin{array}{l}{ }^{18} \mathrm{~F} \text { labeled iron oxide for in vivo PET-CT } \\
\text { imaging }\end{array}$ & {$[34]$} \\
\hline Polymer & ${ }^{99 \mathrm{~m}} \mathrm{Tc}$ & $\begin{array}{l}\text { Scintigraphic images of } \\
\text { tumor targeting }\end{array}$ & $\begin{array}{l}\text { Targeting tumor angiogenesis: comparison of } \\
\text { 99m Tc -peptide and }{ }^{99 \mathrm{~m}} \mathrm{Tc} \text {-polymer-peptide } \\
\text { conjugates }\end{array}$ & {$[35]$} \\
\hline Dendrimers & ${ }^{76} \mathrm{Br}$ & $\begin{array}{l}\text { RGD directed-demdrimers } \\
\text { PET imaging }\end{array}$ & $\begin{array}{l}{ }^{76} \mathrm{Br} \text { labeled RGD-directed-dendritic } \\
\text { nanoprobes for PET imaging of angiogenesis }\end{array}$ & {$[36]$} \\
\hline Streptavidin & ${ }^{111}$ In & Radiotherapeutics & $\begin{array}{l}{ }^{111} \text { In labeled 3-component streptavidin } \\
\left({ }^{111} \text { In-MORF/tat/trastuzmab) nanoparticles }\right. \\
\text { for auger electron induced antisense-mediated } \\
\text { cytoxicity of tumor cells }\end{array}$ & {$[50]$} \\
\hline Immunoliposomes & ${ }^{90} \mathrm{Y}$ & Radiotherapeutics & $\begin{array}{l}\text { Targeted antiangiogenesis of } \alpha_{\mathrm{v}} \beta_{3} \text {-integrin or } \\
\text { VEGFR2 anti-FLK-1 therapy with } \\
\text { nanotargeted therapeutics of } \\
\\
{ }^{90} \text { Y-DTPA-liposome-IA(integrin antagonist) or } \\
{ }^{90} \text { Y-DTPA-liposome-mAb }\end{array}$ & {$[49]$} \\
\hline Immunoliposomes & ${ }^{225} \mathrm{Ac}$ & Radiotherapeutics & $\begin{array}{l}\text { Targeted } \alpha \text {-particles emitters of } \\
{ }^{225} \text { Ac-generators encapsulated in liposomes as } \\
\text { therapeutic agents for micrometastases cancer }\end{array}$ & {$[82-84]$} \\
\hline $\begin{array}{l}\text { Immunoiposomes and } \\
\text { Folate-dendrimers }\end{array}$ & ${ }^{10} \mathrm{~B}$ & Radiotherapeutics & $\begin{array}{l}{ }^{10} \mathrm{~B} \text {-immunoliposomes-anti-EGFR and } \\
{ }^{10} \mathrm{~B} \text {-PAMAM dendrimers-anti-folate } \\
\text { nanotargeted therapeutics for boron neutron } \\
\text { capture therapy (BNCT) }\end{array}$ & {$[51,52]$} \\
\hline
\end{tabular}

small molecules, or involving antibodies or peptides for nanotargeted radionuclide or drug concurrent delivery.

Synergistically integrated nanoparticles with multifunctional and multimodality novel core platform for cancer nuclear imaging and radiotherapeutics have been developed [98]. Important multifunctions include imaging (single or multimodality), therapy (single drug or combination of two or more drugs), and targeting (one or more ligands) with multivalent. For example, binary nanoparticles with two functions could be developed for simultaneous molecular imaging and targeted therapy, ternary nanoparticles with three functions could be designed for simultaneous imaging, therapy and targeting, targeted dualmodality imaging, or targeted dual-modality therapy. Some typical and potential nanoparticles for nuclear imaging and therapeutics are illustrated as follows: (i) radionuclide 

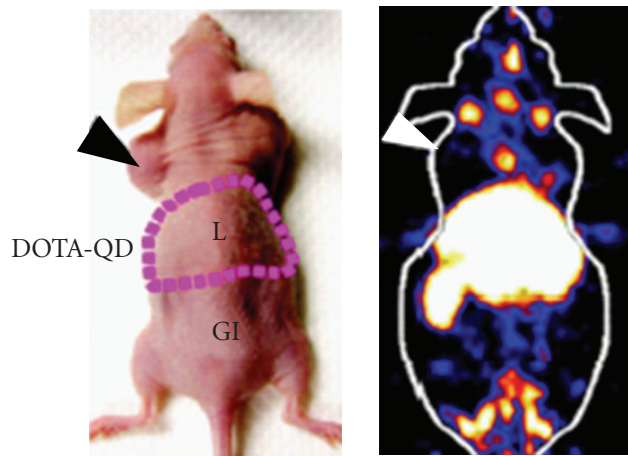

$1 \mathrm{~h}$
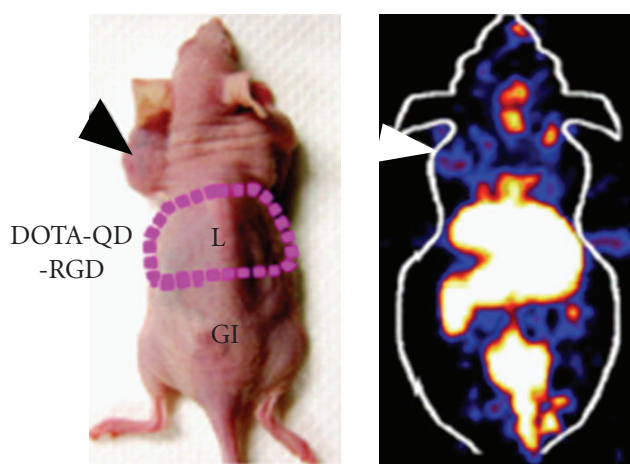

$1 \mathrm{~h}$

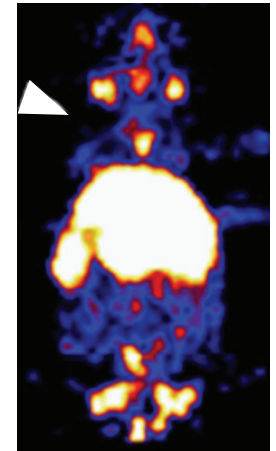

$5 \mathrm{~h}$

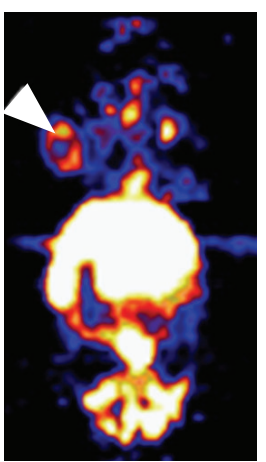

$5 \mathrm{~h}$

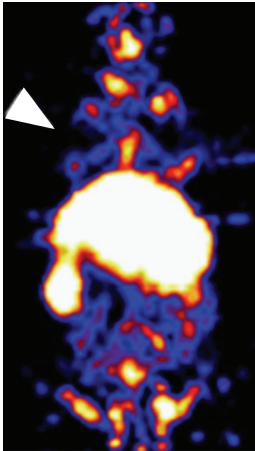

$18 \mathrm{~h}$

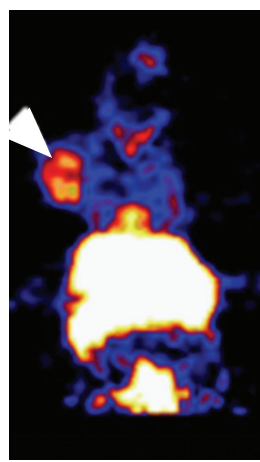

$18 \mathrm{~h}$

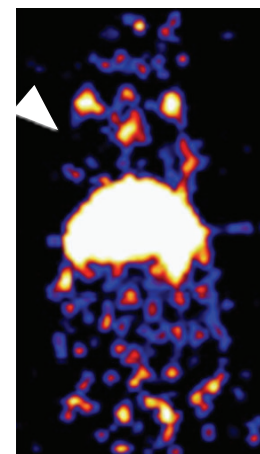

$25 \mathrm{~h}$

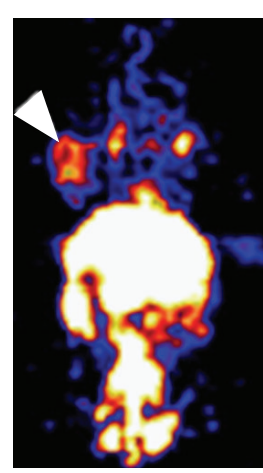

$25 \mathrm{~h}$
$5 \% \mathrm{ID} / \mathrm{g}$

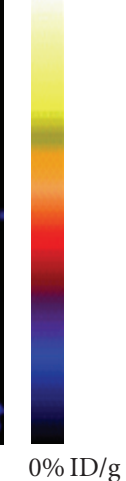

$5 \% \mathrm{ID} / \mathrm{g}$

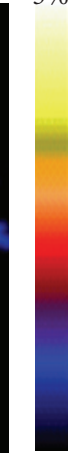

$0 \% \mathrm{ID} / \mathrm{g}$

(a)

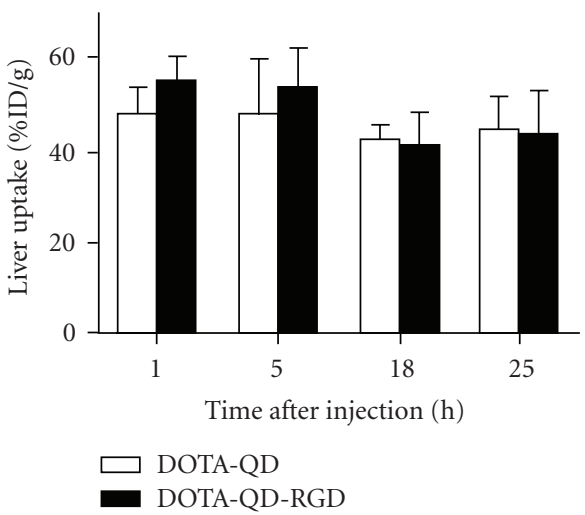

(b)

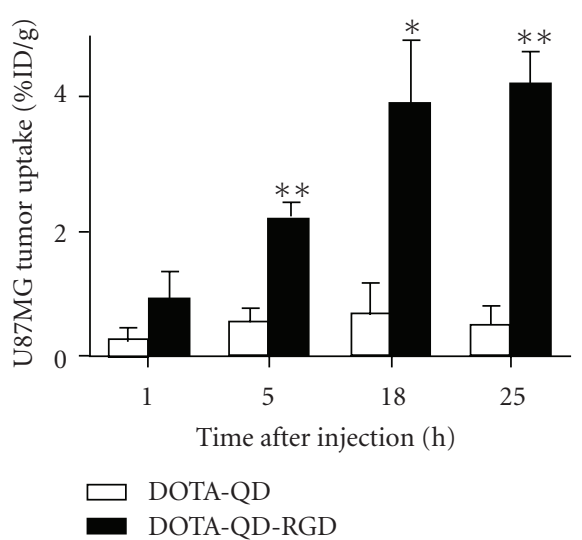

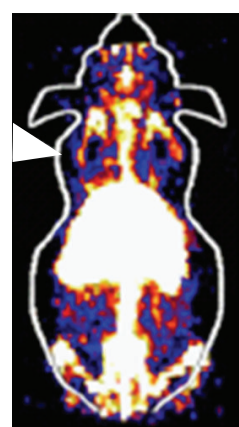

DOTA-QD

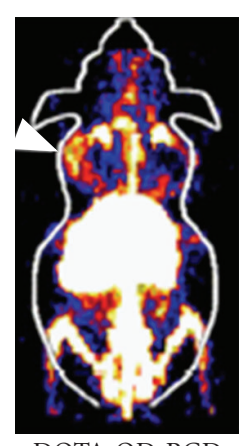

DOTA-QD-RGD (d)

(c)

FIGURE 3: In vivo actively nanotargeted radionuclides of ${ }^{64} \mathrm{Cu}-\mathrm{DOTA}-\mathrm{QD}-\mathrm{RGD}$ for dual-function PET and near-infrared fluorescence (NIR) imaging of U87MG tumor vasculature mice animal model. (a) PET images of ${ }^{64} \mathrm{Cu}$-labeled nanoparticles of DOTA-QD or DOTA-QDRGD. Arrow heads indicate tumors. (b) Liver uptake of ${ }^{64} \mathrm{Cu}$-labeled nanoparticles of DOTA-QD or DOTA-QD-RGD. (c) U87MG tumor uptake of ${ }^{64} \mathrm{Cu}$-labeled nanoparticles of DOTA-QD or DOTA-QD-RGD. (d) Two-dimensional image of the 2 mice shown in (a) at 5 hr after injection (reprinted with permission from reference [37]). DOTA: 1,4,7,10-tetraazacyclodocecane- $\mathrm{N}, \mathrm{N}^{\prime}, \mathrm{N}^{\prime \prime}, \mathrm{N}^{\prime \prime \prime}$ - tetraacetic acid chelators for radionuclides labeling. QD: Quantum dots conjugated with NIR probe. RGD: Arginine-glycine-aspartic acid peptide for targeting tumor angiogenesis integrin $\alpha_{\mathrm{v}} \beta_{3}$.

(e.g., ${ }^{111} \mathrm{In} /{ }^{188} \mathrm{Re} /{ }^{64} \mathrm{Cu}$ )-labeled passively nanotargeted multimodel nanoliposomes [90-92] or actively nanotargeted multifunctional and multimodal immunoliposomes [4547, 99-101], (ii) radionuclide (e.g., ${ }^{18} \mathrm{~F} /{ }^{64} \mathrm{Cu}$ )-labeled iron oxide magnetic nanoparticles for multimodal and multivalent MRI-PET-optical imaging agents and therapeutics
[32-34] (iii) radionuclide (e.g., ${ }^{18} \mathrm{~F} /{ }^{64} \mathrm{Cu}$ )-labeled QDs for multifunctional and multimodal imaging and therapeutics [37-39, 59, 102] and (iv) silica nanoparticles as a platform for multimodality imaging agents and therapeutics [103, 104]. The simultaneous attainment of preferential localization and avoidance of the sequential biological barriers, 
such as RES system uptake, has been studied with a multifunctional multistage delivery system of mesoporous silicon particles for imaging and therapeutic applications [105]. Development of multidrug resistance (MDR) is one of the most challenging aspects of cancer chemotherapy. Bimodality codelivery chemotherapeutics in nanoemulsion formulations has shown to be very effective in enhancing the cytotoxicity in wild-type and resistant tumor cells [106].

\section{Nano-/Radiotoxicology}

Although nanocarriers have provided some new breakthroughs for cancer diagnosis and therapy, the potential adverse human health effects resulting from exposure to nanoparticles should also be a concern [22, 107, 108]. Research shows that nanoparticles can stimulate and/or suppress the immune response, and that their compatibility with the immune system is largely determined by their surface chemistry. Modifying these factors can significantly reduce the immunotoxicity of nanoparticles and make them useful platforms for drug delivery [43]. The biodistribution and movements of nanoparticles through tissues and the phagocytosis and endocytosis of nanoparticles would all likely affect the potential toxicity of nanoparticles. The practical strategies for identifying and controlling interferences in common evaluation methods and the implications for regulation of nanoparticle immunotoxicity have been discussed and suggested [109]; the standardization of nanoparticletuned methods through international "round robin" interlaboratory testing was proposed [109]. Toxicity of nanocarrier systems involves physiological, physicochemical, and molecular considerations. Nanocarrier systems may induce cytotoxicity and/or genotoxicity [110]. To minimize the risks posed by nanomaterials, there are two basic avenues. One is to develop new highly biocompatible nanomaterials with low toxicity. The other is surface modification of nanoparticles with biocompatible chemicals. Many great efforts are being made to develop nanoparticles satisfactory for clinical applications, but nanoregulation is still undergoing major changes to encompass environmental, health, and safety issues $[43,107,108,110]$. QDs larger than the renal filtration threshold quickly accumulate in the RES system following intravenous administration. Great concern has been raised over the use of quantum dots in living cells and animals due to their chemical composition of toxic heavy-metal atoms (e.g., $\mathrm{Cd}, \mathrm{Hg}, \mathrm{Pb}, \mathrm{As}$ ) [59].

Radiolabeled pegylated liposomes have demonstrated effective targeting of solid tumors in patients by nuclear imaging [53]. There were no important adverse reactions attributable to the liposome infusion, and repeated hematological and biochemical profiles performed at day 10 showed no significant changes [53]. Absorbed dose calculations provide a scientific basis for evaluating the biological effects associated with administrated radiopharmaceuticals. In cancer therapy, radiation dosimetry supports treatment planning, dose-response analyses, predications of therapy effectiveness and safety [111]. An analytical dosimetry study for the use of radionuclide $\left({ }^{67} \mathrm{Cu},{ }^{131} \mathrm{I}\right.$,
${ }^{188} \mathrm{Re}$, and ${ }^{90} \mathrm{Y}$ )-liposome in internal radiotherapy has been reported [74]. Unlike the case with radioimmunotherapy, the dose-limiting organ is likely to be the liver, and strategies intended to reduce RES accumulation are needed to further improve such a tumor-targeting approach [74]. We have studied the radiation dosimetric analysis of passively nanotargeted radiotherapeutics of ${ }^{188} \mathrm{Re}$-liposome and radiochemo-therapeutics of ${ }^{188} \mathrm{Re}$-DXR-liposome with OLINDA/EXM software for system-targeted radionuclide therapy. The results showed that the red marrow was to be the critical organ in determining the maximally tolerated absorbed doses, and it was promising and beneficial to carry out further preclinical and clinical investigations [90]. Comparisons with the radiation-absorbed dose estimates for ${ }^{111} \mathrm{In}$ - and ${ }^{90} \mathrm{Y}$-ibritumomab tiuxetan, and the radiation absorbed per unit administered activity (mGy/MBq) for nanotargeted ${ }^{188} \mathrm{Re}$-(DXR)-liposome were much lower in the major organs $[90,111]$.

\section{Conclusions and Future Prospective}

Recent advances in the field of nanotechnology applications in biomedicine offer the promise of better diagnostic and therapeutic options. Medicine and synthetic scientists are making strides in developing nanoconstructs that can be used as core platforms for attaching different functionalities by surface conjugating or after-loading of various nanoparticles for the purposes of cancer molecular imaging and targeted drug delivery. As compared with conventional targeted radionuclide therapy or radioimmunotherapy, the use of nanocarriers can allow for specific multivalent attachment of targeted molecules of antibodies, peptides, or ligands to the surface of nanocarriers. Nanotargeted radionuclide therapy can deliver a high payload of radionuclides, chemotherapeutics, and/or imaging agents to achieve multifunctional and multimodality targeting to tumor cells. The new nanocarrier drug delivery system platform can enhance the efficacy and safety of targeted therapy. Future clinical trial studies are required to translate those advanced technologies to the health care of cancer patients. The optimization of the nanoparticle compositions and structure, the simultaneous attainment of preferential targeting location, reducing immunotoxic effect, and the avoidance of sequential biological barriers of the nanoparticles are the major challenges in the future research and development of passively and actively nanotargeted drug delivery systems.

Several passively nanotargeted radiolabeled nanocarriers have been successfully employed to image and treat tumor models both preclinically and clinically. Future studies should be designed to optimize these novel approaches and to combine targeted delivery, potent radionuclides, imaging agents, chemotherapeutics and/or radiosensitizing agents. We have demonstrated that a co-delivery of radiochemotherapeutics and simultaneous multifunctional imaging is an advantageous characteristic of nanotargeted radionuclides for cancer imaging and therapy. A good multidisciplines and multi-institutes collaboration between the academia, research institutes, and industry combing with an integrated 
"bench-to-clinic" translational approach would accelerate the progress in research of nanotargeted radionuclides toward clinical applications for the healthcare of cancer patients.

\section{References}

[1] K. Strebhardt and A. Ullrich, "Paul Ehrlich's magic bullet concept: 100 years of progress," Nature Reviews Cancer, vol. 8, no. 6, pp. 473-480, 2008.

[2] G. P. Adams and L. M. Weiner, "Monoclonal antibody therapy of cancer," Nature Biotechnology, vol. 23, no. 9, pp. 1147-1157, 2005.

[3] J. M. Reichert and V. E. Valge-Archer, "Development trends for monoclonal antibody cancer therapeutics," Nature Reviews Drug Discovery, vol. 6, no. 5, pp. 349-356, 2007.

[4] P. J. Carter, "Potent antibody therapeutics by design," Nature Reviews Immunology, vol. 6, no. 5, pp. 343-357, 2006.

[5] B. W. Newsome and M. S. Ernstoff, "The clinical pharmacology of therapeutic monoclonal antibodies in the treatment of malignancy; have the magic bullets arrived?" British Journal of Clinical Pharmacology, vol. 66, no. 1, pp. 6-19, 2008.

[6] A. Gabizon, H. Shmeeda, and Y. Barenholz, "Pharmacokinetics of pegylated liposomal doxorubicin: review of animal and human studies," Clinical Pharmacokinetics, vol. 42, no. 5, pp. 419-436, 2003.

[7] T. M. Allen and P. R. Cullis, "Drug delivery systems: entering the mainstream," Science, vol. 303, no. 5665, pp. 1818-1822, 2004.

[8] M. E. Davis, Z. Chen, and D. M. Shin, "Nanoparticle therapeutics: an emerging treatment modality for cancer," Nature Reviews Drug Discovery, vol. 7, no. 9, pp. 771-782, 2008.

[9] M. Ferrari, "Cancer nanotechnology: opportunities and challenges," Nature Reviews Cancer, vol. 5, no. 3, pp. 161-171, 2005.

[10] T. Lammers, W. E. Hennink, and G. Storm, "Tumourtargeted nanomedicines: principles and practice," British Journal of Cancer, vol. 99, no. 3, pp. 392-397, 2008.

[11] K. Kairemo, P. Erba, K. Bergström, and E. K. J. Pauwels, "Nanoparticles in cancer," Current Radiopharmaceuticals, vol. 1, no. 1, pp. 30-36, 2008.

[12] W. E. Bawarski, E. Chidlowsky, D. J. Bharali, and S. A. Mousa, "Emerging nanopharmaceuticals," Nanomedicine, vol. 4, no. 4, pp. 273-282, 2008.

[13] W. R. Sanhai, J. H. Sakamoto, R. Canady, and M. Ferrari, "Seven challenges for nanomedicine," Nature Nanotechnology, vol. 3, no. 5, pp. 242-244, 2008.

[14] D. E. Milenic, E. D. Brady, and M. W. Brechbiel, "Antibodytargeted radiation cancer therapy," Nature Reviews Drug Discovery, vol. 3, no. 6, pp. 488-499, 2004.

[15] J. Y. C. Wong, "Systemic targeted radionuclide therapy: potential new areas," International Journal of Radiation Oncology Biology Physics, vol. 66, no. 2, supplement, pp. S74S82, 2006.

[16] R. M. Macklis and B. Pohlman, "Radioimmunotherapy for non-Hodgkin's lymphoma: a review for radiation oncologists," International Journal of Radiation Oncology Biology Physics, vol. 66, no. 3, pp. 833-841, 2006.

[17] A. J. Davies, "Radioimmunotherapy for B-cell lymphoma: $\mathrm{Y}^{90}$ ibritumomab tiuxetan and $\mathrm{I}^{131}$ tositumomab," Oncogene, vol. 26, no. 25, pp. 3614-3628, 2007.
[18] H. A. Jacene, R. Filice, W. Kasecamp, and R. L. Wahl, "Comparison of ${ }^{90} \mathrm{Y}$-ibritumomab tiuxetan and ${ }^{131} \mathrm{I}$ - tositumomab in clinical practice," Journal of Nuclear Medicine, vol. 48, no. 11, pp. 1767-1776, 2007.

[19] S. H. Britz-Cunningham and S. J. Adelstein, "Molecular targeting with radionuclides: state of the science," Journal of Nuclear Medicine, vol. 44, no. 12, pp. 1945-1961, 2003.

[20] M. Hamoudeh, M. A. Kamleh, R. Diab, and H. Fessi, "Radionuclides delivery systems for nuclear imaging and radiotherapy of cancer," Advanced Drug Delivery Reviews, vol. 60, no. 12, pp. 1329-1346, 2008.

[21] A. Mitra, A. Nan, B. R. Line, and H. Ghandehari, "Nanocarriers for nuclear imaging and radiotherapy of cancer," Current Pharmaceutical Design, vol. 12, no. 36, pp. 4729-4749, 2006.

[22] Y. Liu, H. Miyoshi, and M. Nakamura, "Nanomedicine for drug delivery and imaging: a promising avenue for cancer therapy and diagnosis using targeted functional nanoparticles," International Journal of Cancer, vol. 120, no. 12, pp. 2527-2537, 2007.

[23] S. Sofou, "Surface-active liposomes for targeted cancer therapy," Nanomedicine, vol. 2, no. 5, pp. 711-724, 2007.

[24] I. Ogihara, S. Kojima, and M. Jay, "Differential uptake of gallium-67-labeled liposomes between tumors and inflammatory lesions in rats," Journal of Nuclear Medicine, vol. 27, no. 8, pp. 1300-1307, 1986.

[25] A. L. Klibanov, K. Maruyama, V. P. Torchilin, and L. Huang, "Amphipathic polyethyleneglycols effectively prolong the circulation time of liposomes," FEBS Letters, vol. 268, no. 1, pp. 235-237, 1990.

[26] D. Papahadjopoulos, T. M. Allen, A. Gabizon et al., "Sterically stabilized liposomes: improvements in pharmacokinetics and antitumor therapeutic efficacy," Proceedings of the National Academy of Sciences of the United States of America, vol. 88, no. 24, pp. 11460-11464, 1991.

[27] D. Lasic, "Doxorubicin in sterically stabilized," Nature, vol. 380, no. 6574, pp. 561-562, 1996.

[28] W. T. Phillips, "Delivery of gamma-imaging agents by liposomes," Advanced Drug Delivery Reviews, vol. 37, no. 1-3, pp. 13-32, 1999.

[29] O. C. Boerman, P. Laverman, W. J. G. Oyen, F. H. M. Corstens, and G. Storm, "Radiolabeled liposomes for scintigraphic imaging," Progress in Lipid Research, vol. 39, no. 5, pp. 461-475, 2000.

[30] A. Bao, B. Goins, R. Klipper, G. Negrete, M. Mahindaratne, and W. T. Phillips, "A novel liposome radiolabeling method using ${ }^{99 m}$ Tc-"SNS/S" complexes: in vitro and in vivo evaluation," Journal of Pharmaceutical Sciences, vol. 92, no. 9, pp. 1893-1904, 2003.

[31] W. T. Phillips, B. A. Goins, and A. Bao, "Radioactive liposomes," Wiley Interdisciplinary Reviews. Nanomedicine and Nanobiotechnology, vol. 1, no. 1, pp. 69-83, 2009.

[32] B. R. Jarrett, B. Gustafsson, D. L. Kukis, and A. Y. Louie, "Synthesis of ${ }^{64} \mathrm{Cu}$-labeled magnetic nanoparticles for multimodal imaging," Bioconjugate Chemistry, vol. 19, no. 7, pp. 1496-1504, 2008.

[33] H.-Y. Lee, Z. Li, K. Chen et al., "PET/MRI dual-modality tumor imaging using arginine-glycine-aspartic (RGD)conjugated radiolabeled iron oxide nanoparticles," Journal of Nuclear Medicine, vol. 49, no. 8, pp. 1371-1379, 2008.

[34] N. K. Devaraj, E. J. Keliher, G. M. Thurber, M. Nahrendorf, and R. Weissleder, " ${ }^{18} \mathrm{~F}$ labeled nanoparticles for in Vivo PETCT imaging," Bioconjugate Chemistry, vol. 20, no. 2, pp. 397401, 2009. 
[35] B. R. Line, A. Mitra, A. Nan, and H. Ghandehari, "Targeting tumor angiogenesis: comparison of peptide and polymer-peptide conjugates," Journal of Nuclear Medicine, vol. 46, no. 9, pp. 1552-1560, 2005.

[36] A. Almutairi, R. Rossin, M. Shokeen et al., "Biodegradable dendritic positron-emitting nanoprobes for the noninvasive imaging of angiogenesis," Proceedings of the National Academy of Sciences of the United States of America, vol. 106, no. 3, pp. 685-690, 2009.

[37] W. Cai, K. Chen, Z.-B. Li, S. S. Gambhir, and X. Chen, "Dualfunction probe for PET and near-infrared fluorescence imaging of tumor vasculature," Journal of Nuclear Medicine, vol. 48, no. 11, pp. 1862-1870, 2007.

[38] K. Chen, Z.-B. Li, H. Wang, W. Cai, and X. Chen, "Dualmodality optical and positron emission tomography imaging of vascular endothelial growth factor receptor on tumor vasculature using quantum dots," European Journal of Nuclear Medicine and Molecular Imaging, vol. 35, no. 12, pp. 22352244, 2008.

[39] F. Ducongé, T. Pons, C. Pestourie et al., "Fluorine-18-labeled phospholipid quantum dot micelles for in vivo multimodal imaging from whole body to cellular scales," Bioconjugate Chemistry, vol. 19, no. 9, pp. 1921-1926, 2008.

[40] M. R. McDevitt, D. Chattopadhyay, B. J. Kappel et al., "Tumor targeting with antibody-functionalized, radiolabeled carbon nanotubes," Journal of Nuclear Medicine, vol. 48, no. 7, pp. 1180-1189, 2007.

[41] M. Saad, O. B. Garbuzenko, E. Ber et al., "Receptor targeted polymers, dendrimers, liposomes: which nanocarrier is the most efficient for tumor-specific treatment and imaging?" Journal of Controlled Release, vol. 130, no. 2, pp. 107-114, 2008.

[42] M. Shokeen, N. M. Fettig, and R. Rossin, "Synthesis, in vitro and in vivo evaluation of radiolabeled nanoparticles," Quarterly Journal of Nuclear Medicine and Molecular Imaging, vol. 52, no. 3, pp. 267-277, 2008.

[43] M. A. Dobrovolskaia and S. E. McNeil, "Immunological properties of engineered nanomaterials," Nature Nanotechnology, vol. 2, no. 8, pp. 469-478, 2007.

[44] G. Lucignani, "Nanoparticles for concurrent multimodality imaging and therapy: the dawn of new theragnostic synergies," European Journal of Nuclear Medicine and Molecular Imaging, vol. 36, no. 5, pp. 869-874, 2009.

[45] T. A. Elbayoumi, S. Pabba, A. Roby, and V. P. Torchilin, "Antinucleosome antibody-modified liposomes and lipidcore micelles for tumor-targeted delivery of therapeutic and diagnostic agents," Journal of Liposome Research, vol. 17, no. 1, pp. 1-14, 2007.

[46] T. A. Elbayoumi and V. P. Torchilin, "Enhanced accumulation of long-circulating liposomes modified with the nucleosomespecific monoclonal antibody $2 \mathrm{C} 5$ in various tumours in mice: gamma-imaging studies," European Journal of Nuclear Medicine and Molecular Imaging, vol. 33, no. 10, pp. 11961205, 2006.

[47] S. Erdogan, A. Roby, and V. P. Torchilin, "Enhanced tumor visualization by $\gamma$-scintigraphy with ${ }^{111}$ In-labeled polychelating-polymer-containing immunoliposomes," Molecular Pharmaceutics, vol. 3, no. 5, pp. 525-530, 2006.

[48] G. Hu, M. Lijowski, H. Zhang et al., "Imaging of Vx-2 rabbit tumors with $\alpha_{\nu} \beta_{3}$ - integrin-targeted ${ }^{111}$ In nanoparticles," International Journal of Cancer, vol. 120, no. 9, pp. 19511957, 2007.
[49] L. Li, C. A. Wartchow, S. N. Danthi et al., "A novel antiangiogenesis therapy using an integrin antagonist or anti-Flk1 antibody coated ${ }^{90}$ Y-labeled nanoparticles," International Journal of Radiation Oncology Biology Physics, vol. 58, no. 4, pp. 1215-1227, 2004.

[50] X. Liu, Y. Wang, K. Nakamura et al., "Auger radiationinduced, antisense-mediated cytotoxicity of tumor cells using a 3-component streptavidin-delivery nanoparticle with ${ }^{111}$ In," Journal of Nuclear Medicine, vol. 50, no. 4, pp. 582590, 2009.

[51] X. Pan, G. Wu, W. Yang, R. F. Barth, W. Tjarks, and R. J. Lee, "Synthesis of cetuximab-immunoliposomes via a cholesterol-based membrane anchor for targeting of EGFR," Bioconjugate Chemistry, vol. 18, no. 1, pp. 101-108, 2007.

[52] S. Shukla, G. Wu, M. Chatterjee et al., "Synthesis and biological evaluation of folate receptor-targeted boronated PAMAM dendrimers as potential agents for neutron capture therapy," Bioconjugate Chemistry, vol. 14, no. 1, pp. 158-167, 2003.

[53] K. J. Harrington, S. Mohammadtaghi, P. S. Uster et al., "Effective targeting of solid tumors in patients with locally advanced cancers by radiolabeled pegylated liposomes," Clinical Cancer Research, vol. 7, no. 2, pp. 243-254, 2001.

[54] J. Carlsson, E. F. Aronsson, S.-O. Hietala, T. Stigbrand, and J. Tennvall, "Tumour therapy with radionuclides: assessment of progress and problems," Radiotherapy and Oncology, vol. 66, no. 2, pp. 107-117, 2003.

[55] P. Chen, R. Cameron, J. Wang, K. A. Vallis, and R. M. Reilly, "Antitumor effects and normal tissue toxicity of ${ }^{111}$ In-labeled epidermal growth factor administered to athymic mice bearing epidermal growth factor receptor-positive human breast cancer xenografts," Journal of Nuclear Medicine, vol. 44, no. 9, pp. 1469-1478, 2003.

[56] R. M. Reilly, P. Chen, J. Wang, D. Scollard, R. Cameron, and K. A. Vallis, "Preclinical pharmacokinetic, biodistribution, toxicology, and dosimetry studies of ${ }^{111}$ In-DTPAhuman epidermal growth factor: an auger electron-emitting radiotherapeutic agent for epidermal growth factor receptorpositive breast cancer," Journal of Nuclear Medicine, vol. 47, no. 6, pp. 1023-1031, 2006.

[57] R. M. Reilly, R. Kiarash, R. G. Cameron et al., "111 In-labeled EGF is selectively radiotoxic to human breast cancer cells overexpressing EGFR," Journal of Nuclear Medicine, vol. 41, no. 3, pp. 429-438, 2000.

[58] S. N. Reske, S. Deisenhofer, G. Glutting et al., "111 I-ITdUmediated nanoirradiation of DNA efficiently induces cell kill in HL60 leukemia cells and in doxorubicin-, $\beta$-, or $\gamma$ radiation-resistant cell lines," Journal of Nuclear Medicine, vol. 48, no. 6, pp. 1000-1007, 2007.

[59] A. M. Smith, H. Duan, A. M. Mohs, and S. Nie, "Bioconjugated quantum dots for in vivo molecular and cellular imaging," Advanced Drug Delivery Reviews, vol. 60, no. 11, pp. 1226-1240, 2008.

[60] K. J. Harrington, C. R. Lewanski, and J. S. W. Stewart, "Liposomes as vehicles for targeted therapy of cancer. Part 1: preclinical development," Clinical Oncology, vol. 12, no. 1, pp. $2-15,2000$.

[61] I. Ogihara-Umeda, T. Sasaki, S. Kojima, and H. Nishigori, "Optimal radiolabeled liposomes for tumor imaging," Journal of Nuclear Medicine, vol. 37, no. 2, pp. 326-332, 1996.

[62] K. J. Harrington, C. R. Lewanski, and J. S. W. Stewart, "Liposomes as vehicles for targeted therapy of cancer. Part 2: clinical development," Clinical Oncology, vol. 12, no. 1, pp. 16-24, 2000. 
[63] M. M. Kleiter, D. Yu, L. A. Mohammadian et al., "A tracer dose of technetium-99m- labeled liposomes can estimate the effect of hyperthermia on intratumoral doxil extravasation," Clinical Cancer Research, vol. 12, no. 22, pp.6800-6807, 2006.

[64] G. M. Jensen and T. H. Bunch, "Conventional liposome performance and evaluation: lessons from the development of Vescan," Journal of Liposome Research, vol. 17, no. 3-4, pp. 121-137, 2007.

[65] B. A. Goins, "Radiolabeled lipid nanoparticles for diagnostic imaging," Expert Opinion on Medical Diagnostics, vol. 2, no. 7, pp. 853-873, 2008.

[66] T. Urakami, S. Akai, Y. Katayama, N. Harada, H. Tsukada, and N. Oku, "Novel amphiphilic probes for $\left[{ }^{18} \mathrm{~F}\right]$ radiolabeling preformed liposomes and determination of liposomal trafficking by positron emission tomography," Journal of Medicinal Chemistry, vol. 50, no. 26, pp. 64546457, 2007.

[67] N. Oku, "Delivery of contrast agents for positron emission tomography imaging by liposomes," Advanced Drug Delivery Reviews, vol. 37, no. 1-3, pp. 53-61, 1999.

[68] J. Marik, M. S. Tartis, H. Zhang et al., "Long-circulating liposomes radiolabeled with $\left[{ }^{18} \mathrm{~F}\right]$ fluorodipalmitin $\left(\left[{ }^{18} \mathrm{~F}\right] \mathrm{FDP}\right)$," Nuclear Medicine and Biology, vol. 34, no. 2, pp. 165-171, 2007.

[69] J. W. Seo, H. Zhang, D. L. Kukis, C. F. Meares, and K. W. Ferrara, "A novel method to label preformed liposomes with ${ }^{64} \mathrm{Cu}$ for positron emission tomography (PET) imaging," Bioconjugate Chemistry, vol. 19, no. 12, pp. 2577-2584, 2008.

[70] H.-E. Wang, H.-M. Yu, Y.-C. Lu et al., "Internal radiotherapy and dosimetric study for ${ }^{111} \mathrm{In} /{ }^{177} \mathrm{Lu}$-pegylated liposomes conjugates in tumor-bearing mice," Nuclear Instruments and Methods in Physics Research A, vol. 569, no. 2, pp. 533-537, 2006.

[71] W.-C. Lee, J.-J. Hwang, Y.-L. Tseng et al., "Therapeutic efficacy evaluation of ${ }^{111}$ In-VNB-liposome on human colorectal adenocarcinoma HT-29/luc mouse xenografts," Nuclear Instruments and Methods in Physics Research A, vol. 569, no. 2, pp. 497-504, 2006.

[72] Y.-J. Chang, C.-H. Chang, T.-J. Chang et al., "Biodistribution, pharmacokinetics and microSPECT/CT imaging of ${ }^{188} \mathrm{Re}$ BMEDA-liposome in a C26 murine colon carcinoma solid tumor animal model," Anticancer Research, vol. 27, no. 4B, pp. 2217-2225, 2007.

[73] Y.-J. Chang, C.-H. Chang, C.-Y. Yu et al., “Therapeutic efficacy and microSPECT/CT imaging of ${ }^{188} \mathrm{Re}$-DXR-liposome in a C26 murine colon carcinoma solid tumor model," Nuclear Medicine and Biology, vol. 37, no. 1, pp. 95-104, 2010.

[74] D. Emfietzoglou, K. Kostarelos, and G. Sgouros, "An analytic dosimetry study for the use of radionuclide-liposome conjugates in internal radiotherapy," Journal of Nuclear Medicine, vol. 42, no. 3, pp. 499-504, 2001.

[75] A. Bao, B. Goins, R. Klipper, G. Negrete, and W. T. Phillips, "186 Re-liposome labeling using ${ }^{186} \mathrm{Re}-\mathrm{SNS} / \mathrm{S}$ complexes: in vitro stability, imaging, and biodistribution in rats," Journal of Nuclear Medicine, vol. 44, no. 12, pp. 1992-1999, 2003.

[76] A. Bao, B. Goins, R. Klipper, G. Negrete, and W. T. Phillips, "Direct ${ }^{99 \mathrm{~m}} \mathrm{Tc}$ labeling of pegylated liposomal doxorubicin (Doxil) for pharmacokinetic and non-invasive imaging studies," Journal of Pharmacology and Experimental Therapeutics, vol. 308, no. 2, pp. 419-425, 2004.

[77] W. T. Phillips, R. Klipper, and B. Goins, "Novel method of greatly enhanced delivery of liposomes to lymph nodes,"
Journal of Pharmacology and Experimental Therapeutics, vol. 295, no. 1, pp. 309-313, 2000.

[78] S. X. Wang, A. Bao, S. J. Herrera et al., "Intraoperative ${ }^{186}$ Reliposome radionuclidetherapy in a head and neck squamous cell carcinoma xenograft positive surgical margin model," Clinical Cancer Research, vol. 14, no. 12, pp. 3975-3983, 2008.

[79] C. Zavaleta, B. Goins, A. Bao, L. Mcmanus, C. A. Mcmahan, and W. Phillips, "Imaging of ${ }^{186}$ Re-liposome therapy in ovarian cancer xenograft model of peritoneal carcinomatosis," Journal of Drug Targeting, vol. 16, no. 7-8, pp. 626-637, 2008.

[80] L.-C. Chen, C.-H. Chang, C.-Y. Yu et al., "Biodistribution, pharmacokinetics and imaging of ${ }^{188}$ Re-BMEDA-labeled pegylated liposomes after intraperitoneal injection in a C26 colon carcinoma ascites mouse model," Nuclear Medicine and Biology, vol. 34, no. 4, pp. 415-423, 2007.

[81] T.-H. Chow, Y.-Y. Lin, J.-J. Hwang et al., "Improvement of biodistribution and therapeutic index via increase of polyethylene glycol on drug-carrying liposomes in an HT29/luc xenografted mouse model," Anticancer Research, vol. 29, no. 6, pp. 2111-2120, 2009.

[82] M.-Y. Change, J. Seideman, and S. Sofou, "Enhanced loading efficiency and retention of ${ }^{225} \mathrm{Ac}$ in rigid liposomes for potential targeted therapy of micrometastases," Bioconjugate Chemistry, vol. 19, no. 6, pp. 1274-1282, 2008.

[83] S. Sofou, B. J. Kappel, J. S. Jaggi, M. R. McDevitt, D. A. Scheinberg, and G. Sgouros, "Enhanced retention of the $\alpha$-particle-emitting daughters of actinium-225 by liposome carriers," Bioconjugate Chemistry, vol. 18, no. 6, pp. 20612067, 2007.

[84] S. Sofou, J. L. Thomas, H.-Y. Lin, M. R. McDevitt, D. A. Scheinberg, and G. Sgouros, "Engineered liposomes for potential $\alpha$-particle therapy of metastatic cancer," Journal of Nuclear Medicine, vol. 45, no. 2, pp. 253-260, 2004.

[85] H. Nakamura, M. Ueno, H. S. Ban et al., "Development of boron nanocapsules for neutron capture therapy," Applied Radiation and Isotopes, vol. 67, no. 7-8, pp. S84-S87, 2009.

[86] H. Yanagie, K. Maruyama, T. Takizawa et al., "Application of boron-entrapped stealth liposomes to inhibition of growth of tumour cells in the in vivo boron neutron-capture therapy model," Biomedicine and Pharmacotherapy, vol. 60, no. 1, pp. 43-50, 2006.

[87] K. J. Harrington, G. Rowlinson-Busza, K. N. Syrigos et al., "Pegylated liposome-encapsulated doxorubicin and cisplatin enhance the effect of radiotherapy in a tumor xenograft model," Clinical Cancer Research, vol. 6, no. 12, pp. 49394949, 2000.

[88] P. E. Huber, M. Bischof, J. Jenne et al., "Trimodal cancer treatment: beneficial effects of combined antiangiogenesis, radiation, and chemotherapy," Cancer Research, vol. 65, no. 9, pp. 3643-3655, 2005.

[89] T. Lammers, V. Subr, P. Peschke et al., "Image-guided and passively tumour-targeted polymeric nanomedicines for radiochemotherapy," British Journal of Cancer, vol. 99, no. 6, pp. 900-910, 2008.

[90] C.-H. Chang, M. G. Stabin, Y.-J. Chang et al., "Comparative dosimetric evaluation of nanotargeted ${ }^{188} \mathrm{Re}$-(DXR)liposome for internal radiotherapy," Cancer Biotherapy and Radiopharmaceuticals, vol. 23, no. 6, pp. 749-758, 2008.

[91] L.-C. Chen, C.-H. Chang, C.-Y. Yu et al., "Pharmacokinetics, micro-SPECT/CT imaging and therapeutic efficacy of ${ }^{188} \mathrm{Re}$ DXR-liposome in C26 colon carcinoma ascites mice model," Nuclear Medicine and Biology, vol. 35, no. 8, pp. 883-893, 2008. 
[92] T.-H. Chow, Y.-Y. Lin, J.-J. Hwang et al., "Diagnostic and therapeutic evaluation of ${ }^{111} \mathrm{In}$-vinorelbine-liposomes in a human colorectal carcinoma HT-29/luc-bearing animal model," Nuclear Medicine and Biology, vol. 35, no. 5, pp. 623634, 2008.

[93] Y.-Y. Lin, J.-J. Li, C.-H. Chang et al., "Evaluation of pharmacokinetics of ${ }^{111}$ In-labeled VNB-PEGylated liposomes after intraperitoneal and intravenous administration in a tumor/ascites mouse model," Cancer Biotherapy and Radiopharmaceuticals, vol. 24, no. 4, pp. 453-460, 2009.

[94] K. Kostarelos and D. Emfietzoglou, "Tissue dosimetry of liposome-radionuclide complexes for internal radiotherapy: toward liposome-targeted therapeutic radiopharmaceuticals," Anticancer Research, vol. 20, no. 5A, pp. 3339-3345, 2000.

[95] A. M. Syme, S. A. McQuarrie, J. W. Middleton, and B. G. Fallone, "Dosimetric model for intraperitoneal targeted liposomal radioimmunotherapy of ovarian cancer micrometastases," Physics in Medicine and Biology, vol. 48, no. 10, pp. 1305-1320, 2003.

[96] J. Huwyler, J. Drewe, and S. Krähenbühl, “Tumor targeting using liposomal antineoplastic drugs," International Journal of Nanomedicine, vol. 3, no. 1, pp. 21-29, 2008.

[97] J. W. Park, C. C. Benz, and F. J. Martin, "Future directions of liposome- and immunoliposome-based cancer therapeutics," Seminars in Oncology, vol. 31, no. 13, pp. 196-205, 2004.

[98] J. Cheon and J.-H. Lee, "Synergistically integrated nanoparticles as multimodal probes for nanobiotechnology," Accounts of Chemical Research, vol. 41, no. 12, pp. 1630-1640, 2008.

[99] T. A. Elbayoumi and V. P. Torchilin, "Enhanced cytotoxicity of monoclonal anticancer antibody 2C5-modified doxorubicin-loaded PEGylated liposomes against various tumor cell lines," European Journal of Pharmaceutical Sciences, vol. 32, no. 3, pp. 159-168, 2007.

[100] N. Kamaly, T. Kalber, M. Thanou, J. D. Bell, and A. D. Miller, "Folate receptor targeted bimodal liposomes for tumor magnetic resonance imaging," Bioconjugate Chemistry, vol. 20, no. 4, pp. 648-655, 2009.

[101] A. N. Lukyanov, T. A. Elbayoumi, A. R. Chakilam, and V. P. Torchilin, "Tumor-targeted liposomes: doxorubicinloaded long-circulating liposomes modified with anti-cancer antibody," Journal of Controlled Release, vol. 100, no. 1, pp. 135-144, 2004.

[102] P. Diagaradjane, J. M. Orenstein-Cardona, N. E. ColónCasasnovas et al., "Imaging epidermal growth factor receptor expression in vivo: pharmacokinetic and biodistribution characterization of a bioconjugated quantum dot nanoprobe," Clinical Cancer Research, vol. 14, no. 3, pp. 731741, 2008.

[103] R. Koole, M. M. van Schooneveld, J. Hilhorst et al., "Paramagnetic lipid-coated silica nanoparticles with a fluorescent quantum dot core: a new contrast agent platform for multimodality imaging," Bioconjugate Chemistry, vol. 19, no. 12, pp. 2471-2479, 2008.

[104] M. M. van Schooneveld, E. Vucic, R. Koole et al., "Improved biocompatibility and pharmacokinetics of silica nanoparticles by means of a lipid coating: a multimodality investigation," Nano Letters, vol. 8, no. 8, pp. 2517-2525, 2008.

[105] E. Tasciotti, X. Liu, R. Bhavane et al., "Mesoporous silicon particles as a multistage delivery system for imaging and therapeutic applications," Nature Nanotechnology, vol. 3, no. 3, pp. 151-157, 2008.
[106] S. Ganta and M. Amiji, "Coadministration of paclitaxel and curcumin in nanoemulsion formulations to overcome multidrug resistance in tumor cells," Molecular Pharmaceutics, vol. 6, no. 3, pp. 928-939, 2009.

[107] M. C. Garnett and P. Kallinteri, "Nanomedicines and nanotoxicology: some physiological principles," Occupational Medicine, vol. 56, no. 5, pp. 307-311, 2006.

[108] A. Nel, T. Xia, L. Mädler, and N. Li, "Toxic potential of materials at the nanolevel," Science, vol. 311, no. 5761, pp. 622-627, 2006.

[109] M. A. Dobrovolskaia, D. R. Germolec, and J. L. Weaver, "Evaluation of nanoparticle immunotoxicity," Nature Nanotechnology, vol. 4, no. 7, pp. 411-414, 2009.

[110] K. R. Vega-Villa, J. K. Takemoto, J. A. Yáñez, C. M. Remsberg, M. L. Forrest, and N. M. Davies, "Clinical toxicities of nanocarrier systems," Advanced Drug Delivery Reviews, vol. 60, no. 8, pp. 929-938, 2008.

[111] D. R. Fisher, S. Shen, and R. F. Meredith, "MIRD dose estimate report No. 20: radiation absorbed-dose estimates for ${ }^{111} \mathrm{In}$ - and ${ }^{90} \mathrm{Y}$-ibritumomab tiuxetan," Journal of Nuclear Medicine, vol. 50, no. 4, pp. 644-652, 2009. 


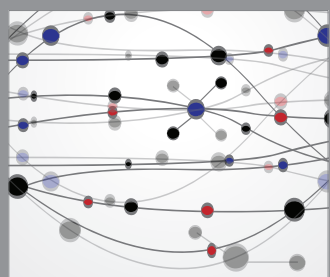

The Scientific World Journal
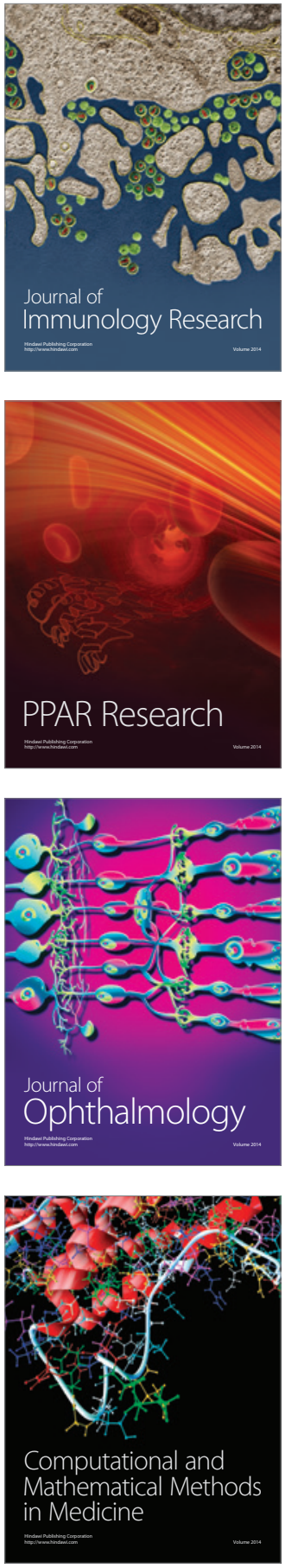

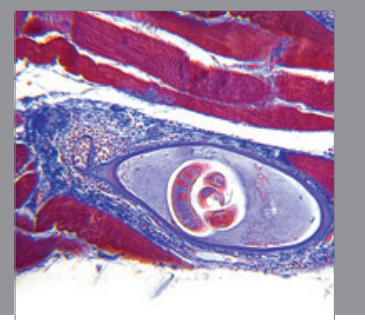

Gastroenterology

Research and Practice
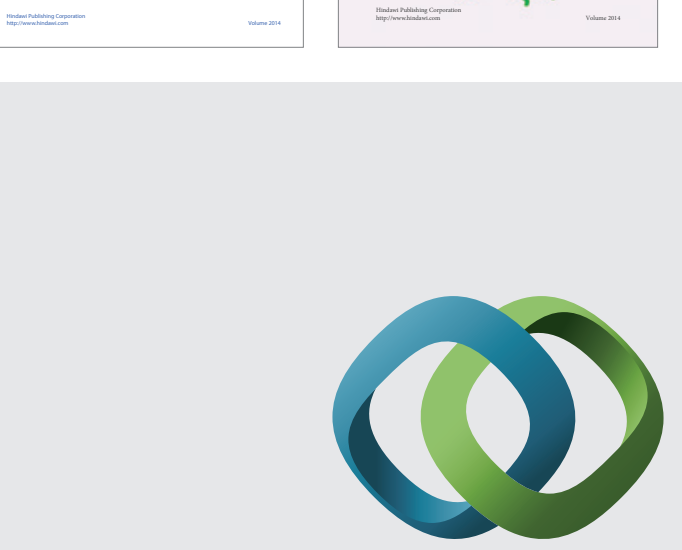

\section{Hindawi}

Submit your manuscripts at

http://www.hindawi.com
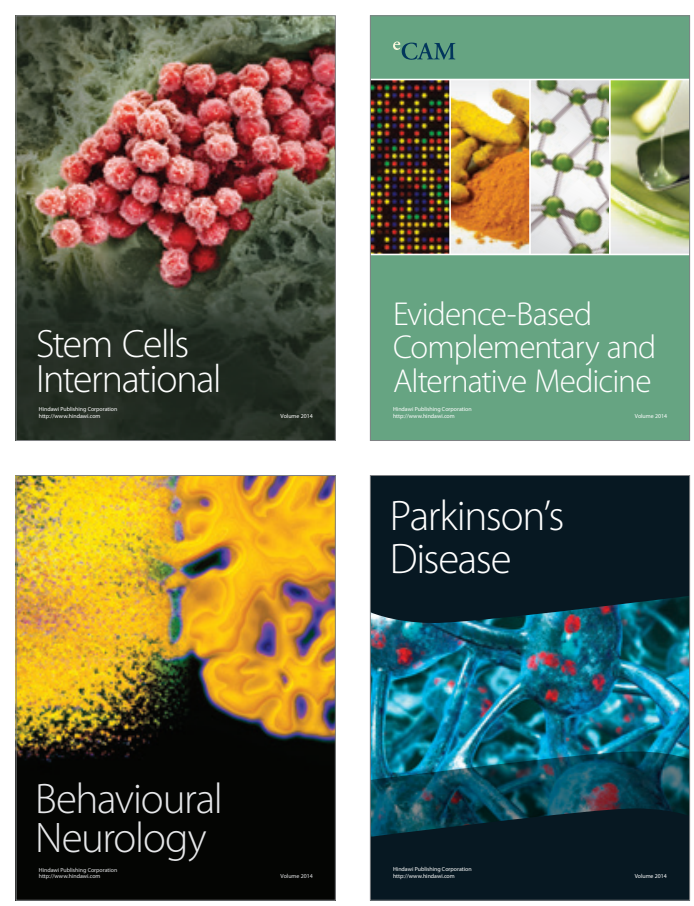

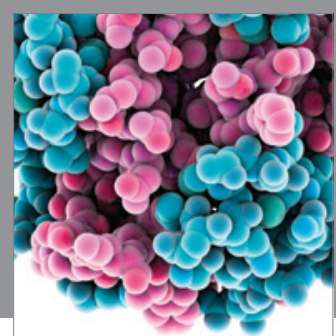

Journal of
Diabetes Research

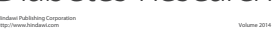

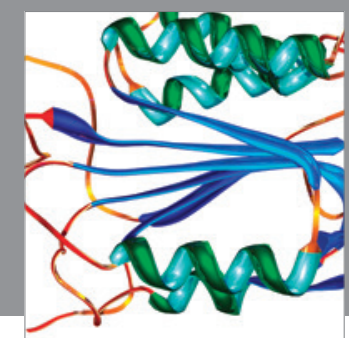

Disease Markers
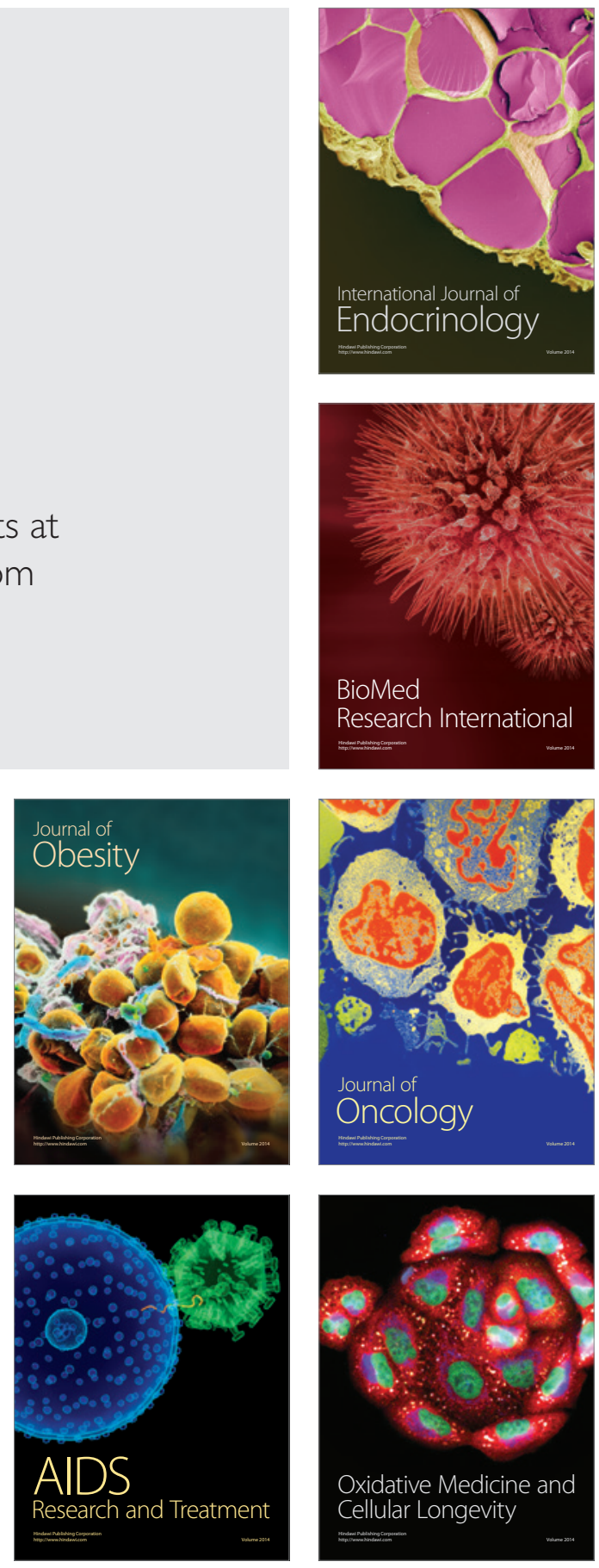